UMR. aling

ON THE ECONOMICS OF LABELS: HOW THEIR INTRODUCTION AFFECTS THE FUNCTIONING OF MARKETS AND THE WELFARE OF ALL PARTICIPANTS

BONROY Olivier ; CONSTANTATOS Christos

- June 2014 -

JEL CODES : L15;L5

Working Paper GAEL ; 2014-03 


\title{
On the Economics of Labels: how their introduction affects the functioning of markets and the welfare of all participants
}

\author{
Olivier BONROY, Christos CONSTANTATOS*
}

June, 252014

Forthcoming in the American Journal of Agricultural Economics

\begin{abstract}
Are labels good or bad for consumers and firms? The answer may seem straightforward since labels improve information, yet economic theory reveals situations where their introduction reduces the welfare of at least some market participants. This essay reviews the theoretical literature on labels in order to identify and explain the main reasons that may cause labeling to produce undesirable side-effects. In contrast to earlier reviews that either concentrate on narrow topics or treat the subject in a more or less informal way, we bring together the main results from all the currently important topics by presenting and discussing the assumptions and modelbuilding underpinning them. The advantage of this approach is that it identifies the origin of the differences between results, thus allowing the synthesis of results that sometimes appear even to be contradictory. We focus on "quality labels" and examine: i) the impact of labeling on market structure; ii) the side-effects of costly certification; iii) issues related to the label's

\footnotetext{
* Olivier Bonroy is tenured research fellow at INRA (French National Institute for Agricultural Research), UMR 1215 GAEL, Université Grenoble Alpes, Grenoble, France. Christos Constantatos is professor in the Department of Economics, University of Macédonia, Thessaloniki, Greece. The authors are grateful to Madhu Khanna, the referees, Claude Crampes, Konstantinos Giannakas, Stephan Marette, as well as participants at the INRA-IDEI seminar "Quality Labels in Agrofood Industry" and at 134th EAAE Seminar "Labels on sustainability: an issue for consumers, producers, policy makers, and NGOs" for their useful comments and suggestions. Responsibility for any errors and omissions is entirely ours.
} 
trustworthiness; iv) the rationale for mandatory $v s$. voluntary labeling; v) the level at which the label's standard is set according to the agency that selects it; vi) the political economy of labels, i.e., pro- or anti-label lobbying, lobbying to affect the label's standard, and lobbying in favor or against the label's mandatory imposition. These topics cover a wide range of applications, including GMOs, Organic Produce, Geographic Indicators, Controlled Origin, Eco-Labels, etc. We conclude by identifying topics that need further research.

Key words: asymmetric information, certification, credence goods, labeling, market power, political economy, regulation, vertical product differentiation, welfare 
The past 30 years have seen the rise of consumers' preferences for various "invisible" attributes whose presence in the purchased good either cannot be verified at all, or would entail verification costs exceed any single consumer's means (credence attributes). Several experimental and/or empirical studies have corroborated the existence of a positive consumer willingness to pay for attributes such as "green", "ethical", "fair-trade", "dolphin safe", "not tested on animals", "organic", "no child labor", "low cholesterol", etc. (see e.g. Disdier and Marette 2012, Hainmueller, Hiscox and Sequeira 2011, Arnot, Boxall and Cash 2006, Noussair, Robin and Ruffieux 2004, Lusk et al. 2005, and Teisl, Roe and Hicks 2002). Many of the aforementioned attributes reveal consumers' preferences for specific production-processes. These preferences are either rooted in the belief that certain types of production provide direct private benefits, mainly health-related (e.g. organic products and foodstuff not containing Genetically Modified Organisms), or stem from ethical issues related to the consumers' desire to pay extra in order to participate in the collective effort to deal with an externality. Consumers often buy an otherwise similar but more expensive variety of a good, just because they believe the way it is produced contributes to environmental protection, dolphin preservation, the fight against poverty or unfair labor conditions, etc.

Credence attributes create severe asymmetric information problems that may have devastating consequences for the related markets, either substantially reducing their trading volume or leading them to total collapse, unless a way is found to assure consumers that their money is well spent. Since not even the good's consumption enables consumers to assess whether a firm's claim is true or false, in markets where credence attributes are important market-devised mechanisms fail to improve information. This leaves direct certification, usually performed by a credible third party, as the only mechanism able to do so. Although tailor-made certification of each product's quality is, in theory, the ideal means for providing information, in practice it faces two challenges: credibility and efficiency. With regard to the latter, note that, since firms may propose many product-types, certifying the exact level of the attribute in every one may be very costly, and provide information 
that is very difficult for consumers to interpret. ${ }^{1}$ For this reason, instead of certifying the exact attributes of any single product, most often the certifying agency defines a standard and certifies whether the quality of an inspected product meets the standard, at least. Products thus certified receive a "label", allowing consumers to distinguish them from other varieties that do not satisfy the established criterion, or have not been inspected (see table 1).

The significant and constantly increasing presence of labeled products, especially in the agrofood sector, has attracted much interest focused on the implications and impact of labels from both a theoretical and a policy perspective. The crucial policy question that all the discussion boils down to is: "are labels good or bad for consumers, firms, and total welfare?" While the answer may seem obvious-after all, the presence of labels reduces information problems-existing theoretical analysis casts many doubts on the unconditional usefulness of labeling. The answer is therefore less straightforward than it might initially appear. An impressive number of studies have produced substantial knowledge on the economics of labels, but since labels can be found in many different contexts, each theoretical work focuses on different questions and uses the technical apparatus that fits its target best. The unfortunate outcome is that the literature on labels abounds with disparate and often apparently contradictory results. In this paper, our intention is to synthesize the key results that have emerged from this literature, while at the same time placing emphasis on the analytics that have generated them.

In response to the need to offer readily available policy guidance, the first studies collecting facts, thoughts, and/or results already available appeared in the literature quite early on. Teisl and Roe (1998) provides an accurate definition of labeling (see next section) and explores its role in dealing with asymmetric information and costly search. Golan, Kuchler and Mitchell (2001) contains an excellent report and discussion of practical issues concerning food labeling, followed by three case studies. Without using formal analysis, that work explores firms' motives for demanding certification, and third parties' incentives to provide it, as well as the role of government in the 
process, from a normative point of view. Crespi and Marette (2003) presents in a rather informal way the main contributions, both theoretical and empirical, related to public labeling. In a volume edited by Krarup and Russell (2005) several authors review specific topics related to information provision-as opposed to command-and-control regulation-as a means to promote environmental issues. In that volume, Teisl and Row (2005) determines a number of factors that influence the effectiveness of eco-labeling programs, namely, compulsoriness (whether all firms are required to provide the information), explicitness (how detailed the information presented to consumers is), standardization of the information presented, and consumer's perception of the credibility of the source providing the information. In the same volume Crespi and Marette (2005) analyzes the conditions for eco-labels to perform better than more traditional tools, such as standards and taxation. Caswell and Anders (2011) introduces a labeling typology according to who owns the label, who performs the certification, and whether labeling is voluntary or mandatory, followed by an analysis of advantages and disadvantages of each identified type, as well as a description of situations where each type of labeling performs better. Recently, Roe, Teisl and Deans (2014) details the arguments for mandatory $v s$ voluntary labeling, by presenting in a thorough but informal way many studies from the related literature. While in this work we review some of the same papers, we opt for a more formal analysis of the topics covered.

The spectacular growing of interest in nutritional labels has sparked a large empirical literature, reviewed in Drichoutis, Nayga and Lazaridis (2011). This literature focuses on the determinants of label use, the debate on mandatory labeling, label formats preferred by consumers, and the effect of nutritional label use on purchase and dietary behavior. Kiesel, McCluskey and Villas-Boas (2011) complements the review in Drichoutis, Nayga and Lazaridis by presenting findings based on three types of data sources: consumer surveys, non-experimental data, and experimental data, distinguishing studies based on market level or natural experiments from laboratory experiments.

Common to all the aforementioned works is the wish to offer guidelines for efficient labeling 
policies, most often applicable to very specific areas. For this reason, they place great emphasis on assembling and presenting results deemed to be relevant to policy prescription, systematically leaving in the background the model-building that generates those results. In many cases the analysis is not formal, and when it is, it focuses on very narrow topics. The present work does not neglect the systematic presentation and interpretation of important results. In that sense it can be seen as providing a significant update to those earlier reviews, also adding topics that at the time were of little importance and/or had not yet been developed. Its more important contribution, though, is that, to our knowledge, this review constitutes the first attempt to synthesize the important results in the literature, by presenting in a systematic way the specific analysis and model-building underpinning them. The advantage of this approach is that it allows direct comparisons between models, thus dispelling apparent contradictions between their results. While we do not neglect the policy-maker and her or his preoccupations, we also aim to help the researcher to grasp in a systematic way the main lines of a literature that has already become quite large, and is still booming.

We identify four main reasons for labels to produce often undesirable side-effects. Firstly, labels interact with market structure, and may influence competition. Secondly, due to the costs they entail (certification and/or monitoring costs) they may create quantity distortions, or even the disappearance of some qualities. Thirdly, labels create incentives for producers to cheat by disguising units of bad quality, which undermines their own credibility. Finally, the labeling agency may not be an unconstrained welfare maximizer. Since both the introduction of a label and the standard at which it is granted affect total welfare and the well-being of particular groups-consumers, firms, and others, such as environmentalist groups-those groups will spent resources in order to either oppose the label's introduction, or influence its level.

We review the theoretical literature on the economics of labels in relation to the aforementioned factors that may make labeling problematic. First we examine in detail the role that labels are expected to play in solving information problems. We then address the key theoretical issue of the 
effects of labels on market structure and the intensity of competition. In the following section, we examine the impact of certification cost on welfare, and address the question of how to regulate the market when the certification process is not $100 \%$ trustworthy. Next, we analyze the label's level as chosen by labeling agencies with different objectives, thus introducing the "political economy" aspect of the label. Finally, we conclude by suggesting an agenda for further research.

\section{The label as an information revealing mechanism}

What is a "label"? Out of the six main definitions one can find online at The Free Dictionary (http://www.thefreedictionary.com/label) we sort out three that may relate to the object under consideration here: 1. An item used to identify something or someone, as a small piece of paper or cloth attached to an article to designate its origin, owner, contents, use, or destination 2. A descriptive term; an epithet 3. A distinctive name or trademark identifying a product or manufacturer, especially a recording company.

In line with definitions 1. and 2. above, Teisl and Roe (1998) offers a narrower definition of a labeling program (or simply labeling) as "... any policy instrument of a government or other third party that somehow regulates the presentation of product-specific information to consumers. This information might describe use characteristics of the product, such as price, taste, and nutrition, or non-use characteristics, such as the environmental impact or moral/ethical elements surrounding the product's manufacturing process." We adopt this definition, although we narrow down its scope for the purposes of this study.

We maintain that goods are consumed for their characteristics (attributes), and that consumers therefore need to know whether the product they plan to purchase contains or not, at least a certain amount of the attributes considered to be the most important. Attributes on which such information is readily available (or can be obtained at low cost) before purchase are called search attributes. While this may be the case for some attributes like freshness (sometimes), other attributes, like taste 
or comfort, cannot be assessed fully by any means other than the good's consumption. Attributes whose presence and/or content can be verified only after purchase, are called experience attributes. Finally, there are some attributes that cannot be verified even after consuming the good; these are termed credence attributes. ${ }^{2}$ A special but very important category of credence attributes relates to the production process, and is referred to as process-attributes, such as "made without child labor," "organic," or "without genetically modified organisms". ${ }^{3}$ Such characteristics are defined by Teisl and Roe (1998) as non-use characteristics.

Even if labels are sometimes used in order to provide information about search or experience attributes (e.g., Michelin stars for restaurants), they represent a rather costly alternative to direct search, trust and reputation. ${ }^{4}$ When it comes to credence attributes, however, these mechanisms become almost powerless, leaving certification by a reputable agent as the only possible mechanism for signaling quality (see Caswell and Mojduszka 1996, McCluskey 2000, and Bonroy 2009). ${ }^{5}$ Hence, for credence goods markets, labels represent the main, if not the only source of reliable information, being in many cases a strict requirement for such markets to even exist.

Labels can be characterized as vertical or horizontal, according to whether they trigger, or not, unanimous consumer reactions to the information they provide. For instance, while it is hard to imagine consumers who at equal prices prefer an unlabeled product to an organic-certified one (vertical label), a label providing accurate information about a product's content in salt or calcium may cause some consumers to avoid its consumption, while making it appealing to others (horizontal labels). The vertical-horizontal characterization of labels providing information about a single characteristic obviously follows the type of the characteristic it certifies. Often though, labels provide information about either multiple, or complex attributes, such as "quality". The position of such labels on the horizontal-vertical dimension crucially depends upon the degree of aggregation of the information provided. According to Teisl and Roe (1998), ISO 14000 negotiations identify two main types of label. Type I labels condense the information about a vector of attributes into a 
one-dimensional score by means of an agreed-upon scoring algorithm. Products with a score above a predetermined level receive a seal of approval (certification). Type III labels disclose information about several product attributes and the disclosure provides either continuous (e.g., grams of fat), or categorical (e.g., high/medium/low risk) information about each element. By their nature, Type I labels are likely to create a unanimous ranking of labeled $v s$. non-labeled products. Such ranking is unlikely with Type III labels, which in most cases are mandatory and borne by all the products in a market. ${ }^{6}$ While many of the results analyzed in this work may apply to more than one label category, our focus is primarily on Type I labels certifying a given level (standard) of a (simple or complex) credence attribute. Such labels are often termed "quality labels."

Minimum Quality Standards (MQS) also certify a minimum quality level, and can help to solve "lemons" type problems in markets with asymmetric information (Leland 1979). In that respect they are quite similar to labels, so some of the results presented in this work may also apply to MQS. However, unlike labels which only inform whether a product meets a quality standard or not, MQS impose mandatory withdrawal of any product that fails to meet the threshold. MQS are sometimes used simultaneously with labels, the former regulate the low, while the latter regulate the high quality. Due to their coercive nature, MQS (but not labels) may have an impact even in environments of perfect information (see e.g. Ronnen 1991, and Crampes and Hollander 1995).

Before concluding the section, some clarifications are required with respect to definition 3. above. Obviously, this definition corresponds to the use of label as a "brand-name", and indeed, in many respects, a brand-name is a Type I label certifying that the labeled product has been produced by a given company. The attribute (origin) is mostly a credence one, and since ceteris paribus all consumers prefer "labeled" to "unlabeled" goods, the brand-name induces vertical differentiation. Due to these similarities, part of the analysis reviewed in this work may also apply to brand-names. However, for all the similarities they share, "brand-name" and "quality label" also have significant differences: a quality label involves third party certification and is usually conferred on products 
supplied by different firms, while a brand-name applies to the products of a single firm which, being the owner of the brand-name, also acts as the certifier. On the one hand, the single ownership of all products under a given brand name eliminates "lemons" type externalities among them, while at the same time affording consumers the opportunity to punish a firm that offers less than the promised quality. Thus, by facilitating reputation, the brand-name constitutes a more effective mechanism in dealing with informational problems related to search and/or experience attributes. On the other hand, because of their self-labeling nature, brand-names are unable to deal with asymmetric information over credence attributes. For this reason, it is very common even for firms with a well-established brand-name to seek labeling of their products by an external certifier.

\section{Label and market structure}

In this section we consider the label's impact on market structure. At this point we assume, for simplicity, that the label is costless and fully reveals product quality, and that consumers' preferences are as in Mussa and Rosen (1978), i.e., each consumer enjoys utility:

$$
U(\theta)=\theta q-p
$$

when consuming a product of quality $q$ sold at a price $p$, where $q$ represents the underlying hedonic attributes that characterize a particular quality. We restrict $q$ to one dimension with larger values of $q$ indicating higher quality levels and define as product line the interval $[\underline{q}, \bar{q}]$. Consumers' valuation of quality varies in proportion to $\theta$, so that the population of consumers is described by the distribution of $\theta$ on the interval $[\underline{\theta}, \bar{\theta}]$. Unless otherwise stated, i) the consumers' distribution is assumed to be uniform with density $\frac{1}{\bar{\theta}-\underline{\underline{\theta}}}$, and ii) the distribution's endpoints are normalized to $\bar{\theta}=1$ and $\underline{\theta}=0$, implying that the market is always uncovered in equilibrium. Finally, we assume that in an environment without label, consumers cannot distinguish a product's quality. When making a 
purchase, depending on the information already available they expect to buy either the base quality $\underline{q}$, or the average quality available on the market given by: $q_{e} \equiv \frac{S_{1}}{S_{1}+S_{2}} q_{1}+\frac{S_{2}}{S_{1}+S_{2}} q_{2}$, where $S_{i}$ represents the quantity supplied of the product of quality $q_{i}, i=1,2$. In some cases they may have exogenous priors about the expected quality of each firm's product.

\section{The market segmentation effect of the label}

Assume, for the time being, that a) there exist only two products of exogenously given quality levels; b) no firm can change the quality of its product; c) there is no entry. Hence, there is a fixed number $n_{2}\left(n_{1}\right)$ of firms selling a given quality $q_{2}\left(q_{1}\right)$, with $q_{2}>q_{1}$. In the absence of labeling both qualities are sold in a single market, while the presence of label segments the market into a high-, and a low-quality sub-markets. We define as the market segmentation effect of the label, the change in market structure due to the emergence of the quality sub-markets. As an example, consider that both qualities can be produced at the same cost and that all the firms are cost-symmetric. Concentration in the pool market as measured by the Herfindahl-Hirshman index is $H H I=\left(n_{2}+n_{1}\right)^{-1}$; after the label's introduction it increases to $H H I_{2}=n_{2}^{-1}$ and $H H I_{1}=n_{1}^{-1}$, in the respective submarkets. Since it is more likely that $n_{2}<n_{1}$, the increase in concentration will be greater for the high quality segment. Even if $n_{1}=n_{2}$, the low quality sellers still face stiff competition from their high-quality rivals, but the latter do not reciprocally feel the same pressure. Entry conditions may also be affected by the introduction of the label. If entry is easy into the low-quality market segment but impossible into the high quality one, labeling results to the replacement of a pool market with easy-entry conditions by two markets, one with easy entry, and the other with blockaded entry.

Zago and Pick (2004) shows that if the labeled high-quality sub-market remains sufficiently competitive, the introduction of the label is welfare enhancing; if, on the other hand, the label substantially increases concentration in that sub-market, its introduction is welfare reducing. Let us complete our base model with a total-industry cost function taking the following form: $C\left(S_{i}\right)=$ 
$\frac{1}{2} b_{i} S_{i}^{2}, \forall i=1,2$, with $b_{1}=1<b_{2}$, in accordance with $q_{2}>q_{1}$. The aggregate behavior of a fixed number of individual producers of each quality can be described as the behavior of a representative producer who maximizes the following profit:

$$
\Pi\left(S_{1}, S_{2}\right)=p_{1} S_{1}+p_{2} S_{2}-\frac{1}{2}\left(b_{1} S_{1}^{2}+b_{2} S_{2}^{2}\right)
$$

High-quality producers have higher cost, and since in the absence of label their superior quality goes unnoticed, they end up being disadvantaged, in terms of both, profits and market share. The label's introduction creates two separate demands for high and low quality, and it follows naturally that $p_{2}^{L}>p^{U}>p_{1}^{L}$, where the subscripts $L, U$, refer to the presence and absence of label, respectively. ${ }^{7}$ If after labeling the emerging high-quality market is competitive, it can be shown that compared to the absence of labeling, at equilibrium prices a) the high-quality market share expands, b) the lower-quality market share shrinks, and c) total sales increase. ${ }^{8}$ The label is welfare increasing (see the first line of table 2). ${ }^{9}$

However, after full information and the resulting product segmentation, the high-quality producers may behave monopolistically, preferring a lower market share at a higher price (compared to the competitive case). If this quantity restriction is substantial, the positive effects of the label may be counterbalanced by its contribution to increasing market power. Surprisingly, by restoring full information the label may reduce welfare! This apparent paradox is explained when one considers the second-best nature of the situation: out of two distortions-market structure and imperfect information-the label corrects only one. If there is no assurance that full information prices will be close to marginal costs, quality revelation is welfare enhancing only when the cost difference between qualities is not too high (see Zago and Pick 2004).

The above conclusions are based on the assumption that under full information, almost all consumers at equal prices strongly prefer product 2 , being ready to pay even a small price premium for it. Only the consumer with $\theta=0$ is indifferent between the two products, always choosing the 
cheaper one. Instead of an atomless point, Matoo and Singh (1994) assumes a mass of consumers with $\theta=0$, distributed according to their willingness to pay for the product. Two consumer groups emerge: one willing to pay different positive premia for an environmentally friendly quality, and the other simply looking at the price and choosing the cheaper product. ${ }^{10}$ Depending on the relative magnitude of these groups, the presence of the quality indifferent group may challenge the inequality $p_{2}^{L}>p^{U}>p_{1}^{L}$, making also possible that $p_{2}^{L} \geq p_{1}^{L}>p^{U}$. While the price of the low quality cannot exceed that of the high quality (otherwise the high quality would attract all the indifferent consumers) it may exceed their common price in the unlabeled equilibrium. By increasing both prices the label may increase the production of both products, thus failing to meet the target for most eco-labels, i.e., to reduce the consumption of the low quality.

\section{The differentiation effect of the label}

By creating two markets, the label affects competition not only within each market, but also between markets. The latter depends of course on the cross-price elasticity between qualities under full information. We define as differentiation effect of the label its effect on competition due to the fact that it allows products to be perceived as imperfect substitutes. This effect is no more than a direct application of an idea initially put forward by Gabszewicz and Thisse (1979), and Shaked and Sutton (1982), in the context of imperfect information. In order to simplify the exposition, we rule out competition issues within each group by considering only two firms, each providing a distinct, exogenously given quality. Assume further that a) both qualities are produced at the same constant marginal cost, equal to zero, and b) when priced at its marginal cost, the low-quality product yields positive surplus to consumers. The label transforms a homogeneous duopoly market into a differentiated one. By revealing the true nature of the low-quality firm's product, the label deprives the low-quality firm from the opportunity to (fraudulently) obtain quality premia, but at the same time provides that firm with the advantage of softer competition from its rival. Assuming 
competition takes place in strategic complements (price competition) the latter impact tends to be stronger than the former. Under imperfect information price-competition drives prices down to marginal cost, i.e., $p^{U}=0$ (Bertrand paradox with homogeneous products). With full information, the high-quality firm may choose to cream consumers with high willingness to pay for quality by charging them a high price $p_{2}^{L}=\frac{2 q_{2}\left(q_{2}-q_{1}\right)}{4 q_{2}-q_{1}}$, thus leaving some room for the low-quality product which obtains a positive market share at $p_{1}^{L}=\frac{q_{1}\left(q_{2}-q_{1}\right)}{4 q_{2}-q_{1}}<p_{2}^{L}$. Competition is relaxed and no firm needs to price at marginal cost: both prices now depend on demand parameters and $\pi_{2}^{L}>\pi_{1}^{L}>0$.

While beneficial for firms, the label's introduction is no good news for some consumers. Instead of purchasing a lottery with a $50 \%$ chance of obtaining the high quality $\left(q_{e}=\frac{q_{1}+q_{2}}{2}\right)$, those with low $\theta$ are obliged to consume a lower quality $\left(q_{1}<q_{e}\right)$ at a higher price $\left(p_{1}^{L}>p^{U}\right)$, and those with the lowest $\theta$ may even leave the market. Among the purchasers of high quality, only those with very high $\theta$ (close to $\bar{\theta}$ ) gain. Those with the relatively lower $\theta$ prefer the lottery of the pre-label situation to the certain purchase of high quality at the prevailing higher price. As a consequence, while it increases welfare, the label always reduces consumers' surplus. ${ }^{11}$ Its overall positive welfare effect is due to its beneficial impact on profits (see table 2). Fully restoring symmetric information through labeling may therefore not be the socially optimal policy, being dominated by a policy that maintains the information asymmetry, while at the same time adjusts the level of the expected quality $q_{e}$ as to maximize social welfare. This explains the result in Baltzer (2011) where a MQS alone generates more welfare than a labeling policy, or a policy combining label and MQS.

The above scenario assumes that in the absence of a label, both the high- and low-quality firms will be in the market. Assume however, along with Roe and Sheldon (2007), the existence of a preliminary stage where each firm decides whether to enter the market and incurs a sunk cost $\varepsilon>0$ upon entry. Without labeling, if two firms enter the market neither of them will be able to $\operatorname{cover} \varepsilon$, since in the eyes of consumers their products are homogeneous and competition is $\grave{a}$ la Bertrand. Hence, in the no label situation, there are two equilibria with only one firm entering the 
market: all consumers expect the quality $q_{e}$ and only those with $\theta>\frac{1}{2}$ purchase at the monopoly price $p^{U}=\frac{q_{e}}{2}$. The label's introduction leads to a situation similar to that described above, but the conclusions about the label's usefulness are markedly different: price competition is intensified, all consumers are better off with the label, and total welfare increases.

Instead of assuming that in the absence of label all consumers expect to purchase the same average quality, let us now assume, along with Gabszewicz and Grilo (1992) and Bonroy and Constantatos (2008), that they have idiosyncratic beliefs about the firm that sells the high quality. Thus, while they all have the same willingness-to-pay for each quality identified with certainty (common $\theta$ ), each consumer is characterized by a subjective probability $\alpha \in[0,1]$ he assigns to the event: "Firm 1 sells the high-quality product and Firm 2 sells the low-quality one." These beliefs may be either the result of a subjective interpretation of some imprecise information or simply gut-feelings. Letting Firm 1 be the low-quality producer, the lower the value of $\alpha$ of a given consumer, the closer to the truth that consumer's beliefs will be. Consumers with $\alpha>(<) \frac{1}{2}$ "trust" the wrong (right) firm, in that they attribute a higher probability to Firm 1 (Firm 2) being the high quality producer. The consumer population is assumed to be distributed over a set of probabilities $\Gamma=[\underline{\alpha}, \bar{\alpha}]$, with $0 \leq \underline{\alpha}<\bar{\alpha} \leq 1$, according to a uniform distribution with density $(\bar{\alpha}-\underline{\alpha})^{-1}$. Both firms know the beliefs distribution, while consumers do not. ${ }^{12}$ Labeling qualities as $h, l$, with $q_{h}>q_{l}$, we write the expected utility a consumer $\alpha$ derives from consuming a product as:

$$
U= \begin{cases}\alpha \theta q_{h}+(1-\alpha) \theta q_{l}-p_{1}, & \text { from consuming good } 1 \\ (1-\alpha) \theta q_{h}+\alpha \theta q_{l}-p_{2}, & \text { from consuming good } 2\end{cases}
$$

Note immediately that prior to the label's introduction, the structure of information creates product differentiation, allowing both firms to survive with positive profit margins. If $\underline{\alpha}<1 / 2<\bar{\alpha}$, differentiation is horizontal, in that, at equal prices consumers are split between the two firms. If $\underline{\alpha}>1 / 2$, or $1 / 2>\bar{\alpha}$, differentiation is vertical, with Firm 1 or 2 , respectively, having the product 
differentiation advantage.

Since differentiation is based on consumers' beliefs, rather than on their tastes, labeling destroys differentiation, resulting in the survival of only one firm. Which firm will survive? If production requires constant marginal costs, with $c_{h}>c_{l}$, the surviving firm will be the one producing the "efficient" product, i.e., the quality with the higher ratio $q_{i} / c_{i}, i=h, l$. This reverse differentiation effect of the label may have adverse effects on profits even when the high quality is the efficient product (see table 2). The low-quality producer resists the label's introduction, since it forces its exit from the market; the high-quality producer who, under full information, becomes a monopolist, selling at price equal to $\theta\left(q_{h}-q_{l}\right)+c_{l}$, may still prefer its niche market in the pre-label situation, where it could charge a higher price to those who trusted its product. ${ }^{13}$ While we consider issues of opposition to the label later on in this paper, it is worth mentioning that this is an instance where the label meets the industry's unanimous opposition.

What happens if the label is "imperfect" in the sense that its message is not perceived by all consumers? Leaving aside "misleading" labels, consider two types of label, the one providing only basic information about the product in a way that is very easy for consumers to grasp (say, a colored stamp), and the other providing very detailed information about the product's characteristics. The former will most likely improve the "unsophisticated" consumers' beliefs, while providing little new information to the "sophisticated" ones; the latter may be totally ignored by unsophisticated consumers-who find it too complicated to bother with-but can improve the beliefs of sophisticated consumers. As a result, while both labels push all the beliefs in the right direction (lower $\alpha$ ), the former reduces their dispersion, while the latter increases it, by modifying accordingly the width of $\Gamma$. Bonroy and Constantatos 2008 shows that, while the introduction of an easy-to-grasp label is always beneficial for consumers, the sophisticated label has two effects: while on the one hand it improves average beliefs, on the other hand it increases differentiation in consumers' perceptions, thus reducing competition and increasing profits. Its overall effect on consumer welfare is ambiguous. 


\section{The ranking effect of the label and the supply chain}

Labeling a final product may also have effects on the markets for that product's inputs, but surprisingly little work has been done on the impact of labels on vertically related markets. ${ }^{14}$ Among alternative inputs, producers always choose the one with the higher pecuniary returns per dollar spent, and if consumers have no preferences regarding the inputs used, pecuniary returns coincide with physical returns per dollar spent. However, as argued in Bonroy and Lemarié (2012) when the more productive inputs happen to meet with consumer disapproval, the full information ranking of input types according to their pecuniary returns per dollar spent may be quite different from that according to their physical product per dollar spent. For instance, fertilizer-intensive production yields higher returns, but consumers consider the quality of the output to be inferior. Similarly, the use of Genetically Modified Organisms (GMO) is cost-saving for producers, but considered harmful by consumers (see Fulton and Giannakas 2004). ${ }^{15}$ With labeling downstream producers rank inputs more in line with consumers' preferences: compared to organic farming both, fertilizers and GMO produce more output per dollar spent, but that output is sold at a lower price. If the latter effect is strong enough, downstream producers may, at equal prices, unanimously prefer organic farming.

Let us, along with Bonroy and Lemarié (2012), consider a two-stage production process. The intermediate product market is a duopoly where two upstream producers sell to a continuum of downstream producers, who transform the input into a final good and sell it to consumers under perfectly competitive conditions. Downstream producers are indexed by a parameter $\omega$, reflecting each one's cost disadvantage and therefore their dependence on the input with the higher physical returns; $\omega$ is uniformly distributed on $[0, \bar{\omega}]$. Downstream producers can identify which input type they purchase, but without a label consumers cannot tell what has been used in producing the product. Since consumers cannot distinguish the goods according to their inputs, final-good producers are willing to pay a higher price for the input that yields more output per unit, i.e., $r_{1}^{U}>r_{2}^{U}$, where $r_{i}^{j}, i=1,2$, $j=U, L$, stands for the price of a given input in the absence and presence of a label, respectively. 
A label allows consumers to express their preference for inputs, and therefore has two effects. First, it creates differentiation in the downstream market, which in turn softens price competition in the upstream market and tends to increase both input prices: $r_{2}^{L}>r_{2}^{U}$, and $r_{1}^{L}>r_{1}^{U}$ (differentiation effect). Second, it affects and potentially reverses the intermediate producers' preference for the two input types, eventually transforming the inequality $r_{1}^{U}>r_{2}^{U}$ into $r_{1}^{L}<r_{2}^{L}$ (ranking effect). Crucial in balancing the differentiation and the ranking effects is the ratio $\frac{\bar{\omega}}{\bar{\theta}}$, which is a relative measure of two heterogeneities: that of downstream producers with respect to the physical returns they can get from the input use $(\bar{\omega})$, and consumers' heterogeneity in the valuation of quality $(\bar{\theta})$. A higher $\bar{\theta}$ increases the differentiation effect by relaxing competition in the presence of labeling, while a higher $\bar{\omega}$ relaxes competition without labeling, thus increasing the importance of the ranking effect.

Who benefits from the label? According to Bonroy and Lemarié (2012), the two effects work together towards driving both prices of the high-quality supply chain up, thus increasing the profits of both participants. The impact of labeling on prices and profits of the low-quality supply chain is ambiguous: the differentiation effect in the downstream market tends to raise the price of the low-quality input, while the ranking effect tends to lower it. The detailed impact of each effect is presented in table $3 .^{16}$

\section{The certification process of the label}

So far, we have assumed that the quality certification related to the attribution of a label is both costless and truthful. In this section we reconsider these assumptions, asking first, "what is the impact of the label's certification cost on producers and consumers' surplus?", and second, "what is the optimal way to regulate the market when the certification process is not $100 \%$ trustworthy?" 


\section{The impact of costly certification}

In order to guarantee the truthfulness and ultimately the credibility of their certification, labeling agencies must incur costs (Crespi and Marette 2001). In some cases, fixed costs, due for instance to general inspection of a firm's premises and production methods, are sufficient for the agency to certify the quality of the firm's entire production (e.g., geographic indicators); in other cases, the certification requires per-unit costs, such as the control of a product's performance or content (e.g., certification of a product's safe performance or of its non-GMO content). In this section we analyze the impact of each type of certification cost (fixed or variable) on market outcome, assuming that labeling agencies charge a competitive price, due to either their non-profit nature or competition in the certification-providing market.

The per-unit cost of certification has similar effects to a specific tax, affecting all actors in the market, even when it leaves the market structure unchanged. As shown earlier, the introduction of a costless label in a competitive market marred by information problems produces benefits for both producers and consumers. Fulton and Giannakas (2004) shows however, that if the label requires a positive per-unit certification cost, $\tau$, this result may not hold. Assuming that demand is not completely inelastic and supply not completely elastic, costly certification will increase the price of the high quality but by an amount less than the increase in the corresponding cost. The latter is partly borne by the certified firm, and if it is substantial relatively to the gain from the certificationinduced outward shift in demand, it will reduce the profitability of the high-quality product, causing some high-quality producers to switch to the production of low quality. The resulting crowding of the low-quality segment leads to a reduction in the low-quality price. Hence, while the per-unit certification cost affects the two prices differently, it tends to reduce individual-firm profits in both market segments and make all producers worse-off. According to Fulton and Giannakas (2004) the producer-surplus loss due to high certification costs may more than offset any surplus gains due to improved information, making the labeling to be welfare reducing. 
When it leaves the market structure unaffected, a fixed certification cost represents no more than a lump-sum payment entirely borne by the certified producers, thus having no impact on price or quantities supplied. However, when it induces some firms to switch from high to low quality in order to avoid its payment, a fixed certification cost may reduce the "excluded" producers profits, along with consumers' surplus. ${ }^{17}$ The latter may opt for sharing the fixed certification costs by forming a producers' association, which generates the necessary revenue by charging individual producers a share proportional to their total output. ${ }^{18}$ This corresponds to transforming the fixed cost to a charge per unit of output produced. Moschini, Menapace and Pick 2008 shows that such marginal cost increases generate a quantity distortion on the high-quality supply, thus calling for public financing of the fixed certification cost. ${ }^{19}$

In the presence of upstream market power, costly certification (whether per-unit or fixed) of the high-quality final product of a supply chain may reduce the surplus even of the purchasers of low quality. Consider again a final product the quality of which depends on the quality of an essential input, and assume, as in Fulton and Giannakas (2004) that the suppliers of the low-quality input have market power (like GM input suppliers) while the high-quality input is provided competitively (traditional seed). In order to avoid the certification cost, some downstream producers switch from high to low quality. This switch increases the price of the high-quality final good, but has an uncertain effect on the price of the low-quality one. The increase of the number of downstream sellers of low quality tends to increase that product's supply and lower its price. At the same time, it increases the demand for the low-quality input, as well as its price, due to the market power of its sellers. The final outcome may be that an increase in certification costs results in higher prices for both products.

\section{Costly certification and mandatory labeling}

While the mandatory status fits well measures such as MQS, it appears at odds with quality labeling, since there is incentive for voluntary labeling. Certification costs, on the other hand, may undermine 
this incentive, since the extra revenue from selling high quality may be insufficient to cover the extra cost. As Roe, Teisl and Deans (2014) puts it "[t]he total cost of labeling, and the distribution of these costs among producer, consumer, and taxpayer, reflects the mechanisms and processes required for each form of labeling." While certification costs per unit of output reduce the high quality's market share, fixed costs may cause its entire disappearance. We show below that in such cases mandatory labeling can be a remedy, but also that it leaves much room for political pressure.

Consider a market with only two qualities, and assume that a) under asymmetric information consumers expect to purchase low quality with probability one; b) under full information both products have positive market share; c) the certification cost is fixed. Under these assumptions, labeling corresponds to the introduction of a new product-the high-quality good-at the expense of an additional fixed cost-the labeling cost. ${ }^{20}$ The introduction of a new product (of same or different quality to the existing one) is socially desirable when the additional surplus it creates outweighs any fixed costs $F$ related to its introduction, and the question is whether the free-market outcome complies with this rule, providing the right incentives for voluntary certification.

In the presence of fixed costs, socially valuable products may not be introduced, due to the "non-appropriability of consumer surplus" (NACS, see Tirole 1989, p. 104). Even at a monopoly position, a firm can capture only a part of the net value its product creates: the remainder becomes consumer surplus. It is then possible that $\Delta \pi<F<\Delta \Pi+\Delta C S$, where $\Delta \pi, \Delta \Pi$, and $\Delta C S$ stand for the change in individual profit, total profit, and consumer surplus, respectively, from the introduction of the new product. The second inequality states that the good is socially desirable, while the first that it is privately unprofitable, and therefore will not be introduced. The problem is exacerbated if the consumption of high quality is also related to positive externalities, i.e., the $C S$ term captures only part of the social value created by the consumption of the high-quality product. ${ }^{21}$

In contrast to MQS where all products must be certified, labeling requires the certification of only the high quality, which cannot be imposed coercively. ${ }^{22}$ Hence, the obvious prescription for 
the NACS problem is to relieve the high-quality producer of a part, or the entire amount of $F$, thus shifting the burden either to the taxpayer or to the low-quality producer (see Carter and Gruère 2003). The former implies direct subsidization of high quality, while the latter can be obtained through a mandatory labeling scheme forcing the low-quality producer to pay at least part of the labeling cost. Mandatory labeling is thus equivalent to a tax-\&-subsidy scheme, providing the high-quality producer with a "stick and carrot" incentive to certify its product: not only is a part of the certification cost (IP cost, in the case of GMO) subsidized, but the profitability of avoiding certification is also lowered. ${ }^{23}$ As the low quality producer receives from this scheme only the stick, mandatory labeling may cause the appearance of the NACS problem at the other end of the quality spectrum: the low-quality product, while socially valuable, may become privately unprofitable. Carter and Gruère (2003) argues that mandatory labeling acts as a barrier banning GM products from the European market, thus defeating what it is meant to defend: consumer's choice.

In order to maintain both products in the market, the regulator may opt for a redistribution of the certification cost only within limits, imposed by the self-selection constraint for the high-quality, and the participation constraint for the low-quality firm. Let $\pi_{i}, i=1,2$, represent the profits of the two qualities with $q_{2}>q_{1}, \pi_{2}=(1+\delta) \pi_{1}$, and $t$ be the percentage of $F$ paid by the high quality. The self-selection constraint for the high quality is $(1+\delta) \pi_{1}-t F \geq \pi_{1}-(1-t) F$, which yields $t \leq \bar{t} \equiv\left(\delta \pi_{1}+F\right) / 2 F$. When $\pi_{2}-\pi_{1}=\delta \pi_{1} \geq F$, or equivalently $\bar{t} \geq 1$, the high-quality firm has sufficient incentives to certify its product, and mandatory labeling can therefore have no other purpose than redistribution. The low-quality participation constraint is $\pi_{1} \geq(1-t) F \Leftrightarrow t \geq \underline{t} \equiv$ $\left(F-\pi_{1}\right) / F$. When $F \leq \pi_{1}$ the low quality stays in the market even if it is held liable for the entire amount of $F .{ }^{24}$ When $0<\underline{t}<\bar{t}<1$, the regulator is constrained to choose a $t \in[\underline{t}, \bar{t}]$, otherwise one of the two qualities will be lost. Mandatory labeling serves efficiency, but the choice of the specific value of $t$ within the admissible interval involves the relative power of the two groups and raises issues of political economy. 
When the low quality is mainly imported, the redistribution of $F$ may also serve protectionist purposes. For instance, setting $t<\underline{t}$ and requiring the imported low quality to pay $(1-t) F$ corresponds to a prohibiting tariff. Using a stylized model, Lapan and Moschini (2004) analyzes trade between the US and Europe of an agricultural product that can be produced as either a GM, or a GM-free crop. Europe produces only the GM-free type, but due to its large needs it imports both. European regulation imposes the payment of IP cost $F$ on the GM-free product and/or some traceability cost $T$ on the GM product. ${ }^{25}$ Since European farms produce no GM products, they are exempt from these costs, which "... act like an import tariff in which the tariff revenue is dissipated" (Lapan and Moschini 2004). By increasing $T$ relative to $F$, the European regulator affects American farmers' incentives, and therefore GM acreage, thus modifying the relative price of the two products. An increase in $F(T)$ increases (decreases) GM acreage, leading to an increase (decrease) of the price of the GM-free product. The impact of these measures on European welfare depends on the relative European imports of the two goods. In the most likely case where Europe imports more of the GM-free good, an increase in $T(F)$ increases (reduces) European welfare.

\section{Trustworthiness of the label}

Suppose now that firms can cheat about their product's certification of their product by making false claims, affixing imitations of the genuine label, or inserting low-quality units into the certified product. Consumers' deception caused by misleading labeling affects their trust in the labeling process, which has detrimental consequences for the market acceptance of genuinely certified products (Giannakas 2002). The government must monitor the high quality firms in order to protect the label's credibility and avoid a lemons-market outcome. Assume for the moment that cheating is costless and consider a competitive market with free entry. Before firms make any quality decision, the government announces that, among all high-quality labeled firms, a number $m$ of randomly chosen ones will be inspected. Inspections are costly, reliable, and result in firms caught cheating having to pay 
a fixed fine $F$. Choosing $m$ so that the expected penalty just offsets the expected gain from cheating may be cost saving, since it replaces certification of all the high-quality firms by the inspection of only a percentage of them. Moreover, by transferring the burden of proof from the labeling to the monitoring stage, it allows firms to self-label their products. Baksi and Bose (2007) compares selfwith third-party labeling, assuming that a) the former is costless, b) the latter requires a fee per unit of certified output, and c) a low quality firm can cheat either by using fake and costless labels (under third-party labeling) or by pretending to be a high-quality firm (under self-labeling). Compared to costless self-labeling, third-party labeling requires an additional cost, but in exchange it may reduce inspection costs. Third-party labeling acts as a per unit tax on high quality: it increases the price, and reduces the number of firms in the high-quality market-segment. The price increase also increases the low-quality firms' incentive to cheat, thus forcing the government to inspect more firms (incentive effect). The cost-induced shrinking of the high-quality segment allows the government to inspect fewer firms (market share effect). The relative strength of these two effects determines whether third-party labeling reduces inspection costs, and determines the optimal labeling option. Baksi and Bose (2007) shows that in most cases self-labeling emerges as the socially optimal option, third-party labeling being optimal only when the per-unit monitoring cost is high and/or the number of firms to be monitored is low (i.e. when the market share effect substantially exceeds the incentive effect). ${ }^{26}$

An ideal label must be unit-specific, testing and certifying individually every single productunit. Since this is often very costly, labels are usually firm-specific, certifying the quality of a firm's total production, after inspecting that firm's production premises, its production methods, and/or a sample of its output. We call this a collective label in that it is attributed to all the units of the firm, including some that have not been inspected. ${ }^{27}$ When the entire production of an industry is of either high or low quality (as has been assumed so far), it makes no difference whether the label is firm- or unit-specific. When, however, product quality may vary from unit to unit, a certified firm can hide 
low-quality units in its sales of labeled products. The resulting fraud damages the reputation of the label, thus producing a negative externality that affects all firms. ${ }^{28}$

Let us now assume that fraud is no longer costless: in addition to any certification cost that must also be borne by the honest firm, a cheating firm must bear a per-unit cost of disguise, $d$. Despite the latter, fraud can be rewarding if the production of a "disguised" high-quality unit is less costly at the margin than the production of a truly high-quality good. ${ }^{29}$ Defined as purity level $(\rho)$ in a labeled-products market, the proportion of high-quality product sales out of total sales is:

$$
\rho=\frac{S_{2}^{L}}{S_{2}^{L}+S_{1}^{L f}}
$$

with $S_{1}^{L f}$ representing the sales of low-quality products hidden in the sales of labeled products. When $\rho$ is perfectly anticipated by consumers, any increase in its value results in a collective reputation incentive, shifting outwards the market demand function and benefiting all the certified firms. However, as the quality of a credence good cannot be verified even after consumption, individualfirm reputation is impossible to build. It is, therefore, in the interest of each firm to include some amount of "disguised" products in its supplied quantity (adverse selection incentive). As is typical with inter-firm externalities, market structure is crucial for the equilibrium value of $\rho$. Under competition the effect on $\rho$ of an individual firm's purity is negligible, therefore in equilibrium $\rho=0$, and the collective reputation incentive disappears taking with it the entire market for labeled products. Under monopoly, any impact on sales' purity is fully internalized: adverse selection disappears and $\rho=1$. Under oligopoly, both effects are present, and their relative strength determines the market outcome. The higher the number of firms, the more likely it is that the adverse selection incentive will prevail over the collective reputation one.

As shown in Hamilton and Zilberman (2006), imposing a positive per-unit certification cost $\tau$ may increase the level of purity in the market. ${ }^{30}$ This somewhat surprising result is due to the fact that, like a tax on high quality, the certification cost raises the price of high quality, but by an amount 
less than $\tau$. Since-contrary to Baksi and Bose (2007)-the cheating low-quality firm must also pay the certification cost, imposing and/or increasing $\tau$ reduces the marginal return from disguising low-quality units, and discourages fraud. Again like a tax on high quality, the per-unit certification cost reduces the high quality's market share. The average quality of the labeled product increases, but fewer consumers buy that product. This reduction in market share may also end up reducing the labeled firm's profit, as can easily be seen in the extreme case of a market with unit purity: any further increase in the per-unit certification cost cannot improve purity, yet it reduces the sales, and thus the profit of the high quality firm.

An increase in purity can also be achieved by monitoring, and penalizing firms caught cheating. The introduction of a monitoring-punishing system has two effects. First, because the equilibrium number of inspected firms is $m^{*}=m^{*}(\rho)$, with $m^{\prime}<0$, firms now have an additional collective interest in seeing the average purity in the market raised: a higher value of $\rho$ reduces the government's optimal number of inspections, and therefore the probability of any individual firm being inspected. Second, for any given probability of inspection, a higher individual purity level assures a firm a lower probability of detection. ${ }^{31}$ While any given purity level $\rho$ in the high-quality market can be achieved through either the imposition of a positive per-unit certification cost or the introduction of a monitoring-punishing system, the latter is welfare superior since it achieves $\rho$ without reducing the size of that market.

Finally, note that the certification process itself may also be untrustworthy. When the certification agency uses the certification fee for raising revenue instead of just covering certification costs (like a non-profit agency), it may have an incentive to deceive consumers. In such cases, the label loses its information value, unless the agency is able to convince consumers of its good intentions. Mahenc (2009) shows that the agency may build a bayesian reputation by using the (per-unit) certification fee as a signal. The main result is that the agency may charge fees that exceed the Ramsey level, in order to prove its trustworthiness. The resulting label creates a welfare loss by 
further reducing consumption compared to the case of a label provided by a trustworthy (non-profit) agency.

\section{Optimal labeling standard and welfare}

When product qualities are exogenously determined at some levels that consumers know but are unable to identify, the labeling standard is of little importance. For instance, in a market with two exogenous qualities, full information can be restored by a single label at any standard between the low and the high quality. More generally, with $n \geq 2$ products of exogenous quality, the presence of $n-1$ labels, each set at any standard between a pair of adjacent qualities guarantees the full information outcome. Only when the number of labels is $k<n-1$ will some qualities be bunched under the same label, thus leaving consumers unable to distinguish one from another.

When firms can choose the quality level of their product, the number of labels and the standard at which each label is set become of paramount importance, since they determine the set of qualities supplied in equilibrium. Discrete labels at predetermined levels provide only a rough discrimination of qualities, since they simply certify that a product's quality is not inferior to a threshold level, without allowing comparisons among qualities satisfying the criterion. With a continuous range of potentially available qualities, the full-information quality configuration can be obtained only through a continuum of labels, i.e., a tailor-made certification of any product's quality. Since the latter is very costly and provides information that is difficult for consumers to grasp, certification through a limited set of discrete labels may represent the only feasible compromise. However, discrete labeling has an important consequence: it affects quality decisions. If a firm chooses a quality lower than the label's level it cannot have its product labeled, while choosing a higher quality implies paying the cost of additional quality without being able to reap the benefit. Thus, with endogenous quality choices out of a continuum of feasible levels, introducing a set of labels practically corresponds to a soft way of regulating quality levels. While we have found little work on the 
optimal number of labels-usually there are exogenously assumed to be one or two labels-there is a substantial literature relating the label's standard to the regulator's objective. ${ }^{32}$ The related literature distinguishes certification by the following types of standard-setting agents according to their objectives, and compares the corresponding label levels: a) government, maximizing total welfare; b) non-government organization (NGO), maximizing or minimizing a specific benefit or harm, usually related to some externality (eco-labels are prime examples of this category); c) the industry. ${ }^{33}$ In what follows, we first discuss private vs. public labels, then consider labels set by NGO's, and finally examine the literature on the political economy of labels.

\section{Private vs. public labels}

We start by comparing labeling standards set by the industry to those set by a social planner. The question of whether the industry-set standards are too high or too low admits no universal answer, as the two most oft-cited examples, ecolabels and Geographic Indicators standards, attest. While industry-implemented ecolabels are typically criticized for being too lenient, GI standards set by producers' associations are often criticized for being unnecessarily demanding. In what follows we try to isolate all factors producing a bias in one or the other direction, and table 4 summarizes our results.

Demand effect. Because no firm can convince consumers that it sells products of a higher quality than the certified level, making the label stricter increases consumers' willingness-to-pay for the certified quality. We call this the demand effect. Since we assume that the social planner and the firm face the same-monotonically increasing in quality-cost function, comparing the intensity of the demand effect between these two potential standard-setters is the most important building block of the analysis. According to Spence (1975), this issue can be addressed in general terms only if we restrict both agents to producing the same quantity and examine how a quality increment affects the marginal willingness-to-pay of the marginal and the average consumer. If, following a 
quality increment the willingness-to-pay of the average consumer increases more than that of the marginal consumer, the monopolist undersupplies quality, and vice-versa. ${ }^{34}$ From expression (1) we get $\frac{\partial^{2} U}{\partial q \partial \theta}=1>0$, and willingness-to-pay for quality increments decreases with quantity, which is inversely related to $\theta$. For this standard utility function the marginal willingness-to-pay of the average consumer is less than that of the marginal consumer, hence, the demand effect induces an industry-set standard at a lower level than the social optimum.

Spence's argument is depicted in figure 1. Lines $D_{1}\left(q_{1}\right)$ and $D_{2}\left(q_{2}\right)$ represent the demand functions before and after the quality increment, respectively. Since each consumer buys only one unit, the quantity axis represents a decreasing ranking of $\theta$ 's. Assume that (1) holds, and that initially quality $q_{1}$ is sold at price $0 a$, and purchased by the entire segment $[\widetilde{\theta}, \bar{\theta}]$. Keeping quantity constant, the monopolist decides whether to replace $q_{1}$ by $q_{2}$ by comparing the area abcd against the cost difference between the two qualities, while the social planner uses the area $f b c e$ to perform the same test. For demand functions deriving from (1) it is obvious that $f b c e>a b c d$, therefore, compared to the monopolist, the social planer has greater incentives to adopt any given quality increment. $^{35}$

Strategic effect. Assume that the value of the base quality is $\underline{q}>0$, and the production of any quality level requires a fixed cost $F(q)$, with $F^{\prime}>0, F^{\prime}>0$, and $F(\underline{q})=0$. Assume further that the certification cost is not too high, and the width of the taste-range sufficient to support two products in equilibrium: an unlabeled one of quality $\underline{q}$ and a labeled one of quality exactly equal to the label's standard. Let the base-quality sector be competitive with free entry, and the highquality one a monopoly. According to our previous analysis an industry-set standard will be lower than the socially optimal one. If, however, the base quality is also produced by a single firm, the duopolists' interaction brings a strategic effect into the picture: the high quality producer knows that an increase in $q_{2}$ increases differentiation, thereby inducing a softer rival price reaction. The strategic effect tends to raise the standard and make it ceteris paribus higher than the socially optimal 
one. This result is reinforced by the fact a social planner who cannot regulate prices at the second stage has an incentive to set the socially optimal standard at an even lower level, precisely in order to reduce differentiation and obtain tougher price-competition. ${ }^{36}$ In order to compare the strength of the demand and strategic effects, combine (1) with a fixed-cost function, $F(q)=q^{2} / 2$. Under full information, standard calculations (see Motta 1993) show that the duopoly Nash-equilibrium is $\left(\left(p_{1}^{N}, q_{1}^{N}\right),\left(p_{2}^{N}, q_{2}^{N}\right)\right)$ where $q_{1}^{N}=.0482, q_{2}^{N}=.2533$. In order to simplify the exposition, assume that $\underline{q}=q_{1}^{N}$. Under imperfect information, the high-quality firm wishes to produce and certify the quality level $q_{2}^{N}$, but the social planner's ideal standard is at $q_{2}^{S}=.3752>q_{2}^{N}$. As the demand effect is stronger than the strategic effect, the privately-set standard is lower than the socially optimal one. ${ }^{37}$

Up to this point we have assumed that the price-quality decision of the high-quality product is made by a single firm, or equivalently a fully-coordinated cartel. In many instances, though, the high-quality product is produced by a group of producers led by an organization that controls labeling requirements and standard promotion expenses, but has no control on individual quantities. Such is the case of products characterized by geographical indicators (GI): a central organization defines the necessary production requirements for a firm to label its product, monitors compliance with these requirements in order to protect the collective reputation of the label, and eventually assumes some promotion expenditures. ${ }^{38}$ In the absence of production quotas, the price of the product will always be equal to the individual firm's marginal production cost. Following the analysis in Mérel and Sexton (2012) we will discuss below how a GI organization that cannot restrict total supply using quotas may be able to increase its members' profits by properly manipulating the labeling standard. ${ }^{39}$

Profit margin effect. ${ }^{40}$ Suppose for a moment that an increase in $q$ increases demand without affecting variable cost. Since $p=M C$ due to competition, an individual firm's average profit at any given quantity is the difference $M C-A C$, where $M C, A C$, stand for marginal and average 
cost, respectively. If the marginal cost rises faster than the average cost, any outward shift of the demand will produce higher profit margins over a higher volume of sales, thus increasing the private regulator's incentive to raise the standard. As pointed out in Spence (1975), "when constrained to set price equal to marginal cost, the profit maximizing firm does not set quality at the optimal level." Mérel and Sexton (2012) finely illustrates this by showing that, when the variable cost function has elasticity greater than 1 with respect to both changes in quality and changes in quantity, the profitmargin effect will always induce the private regulator to set a standard above the social optimum. ${ }^{41}$

Supply restriction effect. Increasing a firm's marginal cost induces a less aggressive behavior. Simultaneously increasing the marginal cost of all the firms in a sector reduces total supply and increases price. ${ }^{42}$ While competition ensures that at the margin profits are always zero, the higher price may increase the producer surplus form the inframarginal units, despite the marginal cost increase. If, following a change in product specification producer surplus from inframarginal units increases, and sufficiently so as to compensate for the reduction in sales, then total producer surplus may increase, even if the change has no value for consumers. For this to happen, i.e., for restricting supply through higher standards to be a feasible and profitable strategy, three necessary (but not sufficient) conditions must be met: variable costs must be increasing in quality and in quantity, and for any given quality, as quantity increases marginal cost must rise faster than average cost. Figure 2 (inspired from Mérel and Sexton 2012) depicts the situation. $M C_{0}=M C\left(S ; q_{0}\right), M C_{1}=$ $M C\left(S ; q_{1}\right)$ show the marginal cost function at two different levels of production requirements, with $q_{1}>q_{0}$. For simplicity, we assume, as in Bouamra-Mechemache and Yu (2012), that stricter production requirements provide no additional utility to consumers: granting the label at quality level $q_{1}$ instead of $q_{0}$ simply increases cost without affecting demand. However, producer surplus under the $q_{1}$ specification may be higher compared to that under $q_{0} \cdot{ }^{43}$ Obviously, no social planner would ever want to impose such an unproductive increase in quality, but the organization may opt for it. It is obvious that starting from low values of $q$ the supply-limiting effect on producer surplus 
is significant, but starts decreasing for further increases in $q$, eventually reaching negative values. Hence, if the socially optimal standard is relatively low, both the profit-margin effect and the supply restriction effect induce the private regulator to adopt a higher standard. However, if the social standard is relatively high, then the profit-margin effect still biases the private regulator's standard upwards, but the supply restriction effect works in the opposite direction. The conclusion in Mérel and Sexton (2012) is that at the socially optimal standard, the profit margin effect is always strong enough to cause (whether concurred or countered by the supply limiting effect) the industry-set standard to exceed the socially optimal one.

Reservation-quality effect. In a study of GMO-free grain markets, Lapan and Moschini (2007) points out that, since the two types of grain share common handling premises, the presence of some GMO into the GMO-free product is almost unavoidable. Since 100\% purity of the GMO-free product is either impossible or highly uneconomical, the question is at what purity level a product can be labeled as GMO-free. In line with the above analysis, farmers in Lapan and Moschini (2007) desire a higher purity level than the socially optimal one. While some of the factors identified in Mérel and Sexton are still at work, the Lapan and Moschini (2007) analysis is worth a closer look, since it uses the following utility function, quite common in the GMO literature:

$$
U_{i}=\left\{\begin{array}{cc}
u-\theta s_{i}-p_{i} & \text { if quality } i \text { is purchased } \\
0 & \text { in case of no purchase }
\end{array}\right.
$$

with $s_{i}$ corresponding to the degree of "impurity" of product $i$, i.e., the percentage of GM ingredients that one can find in a GM-free product. Since $s_{i}=1-q_{i}$, translating the "bad attribute" to "good attribute", one can write this utility function as $U_{i}=(u-\theta)+\theta q_{i}-p_{i}$, which, in turn, is equivalent 
to:

$$
U_{i}=\left\{\begin{array}{cc}
\theta q_{i}-p_{i} & \text { if quality } i \text { is purchased } \\
\max \{\theta-u, 0\} & \text { in case of no purchase }
\end{array}\right.
$$

which is "almost" similar to (1), except that for the consumer group characterized by $\theta-u>0$, the market participation constraint, $\theta q_{i}-p_{i}-(\theta-u)>0$, becomes more stringent and decreasing in $\theta$. At any price-quality set, the high $\theta$ consumers are now more likely to abandon the market. Consider a potential quality increment to the basic quality offered at a given price. For those high- $\theta$ consumers who do not purchase the basic quality, the additional benefit from a quality increment must be measured against their non-purchase utility. Since the latter is higher than their utility from the basic quality, the social planner's incentive for providing the quality increment is weakened. At the same time, the quality increment induces some high- $\theta$ consumers to purchase, thus making the monopolist more eager to provide it. As a result, even if still holds that $\frac{\partial^{2} U}{\partial q \partial \theta}=1>0$, a monopolist may overprovide quality compared to the social planner's wish.

Returning to figure 1 , the utility function in (6) involves a "demand function" for the nopurchase option, such as line $H .{ }^{44}$ Note that consumers in the $[\widehat{\theta}, \bar{\theta}]$ segment no longer participate in the market. Compared to the case corresponding to (1), on the one hand, the monopolist's incentive to improve quality increases by the area $0 k w a$, since those consumers were not representing sales when $q=q_{1}$, and on the other hand the social planner's gain from such improvement is reduced by the area $e f g$, since the increase in total consumers surplus for the $[\widehat{\theta}, \bar{\theta}]$ segment is only egv. It may well be that $e f b c-e f g<a b c d+0 k w a$, in which case the monopolist is more eager to adopt any given quality increment than the social planner. This is an additional reason to those presented in Mérel and Sexton (2012) for arguing that private labels will be granted at quality levels higher than the social optimum.

Comparing the privately-set label to the socially optimum standard, we conclude that when the 
labeling agency is not interested in controlling the high-quality product's supply (perhaps because competition in the high-quality sector is already weak) the demand effect tends to lower the standard below its socially optimal level, while both the reservation-quality and the strategic effects tend to reverse this conclusion (see table 4). Our simple numerical example showed that in a model using preferences as in (1) and a quadratic cost function, the industry-set standard is lower than the socially optimal one. If on the other hand the labeling agency intends to coordinate the production of high quality, the profit-margin effect, whether supported or countered by the supply-restriction effect, predominates over everything else and the industry-set standard is too high.

\section{Labels set by NGOs}

We consider NGOs to be organizations intervening in markets where, besides the informational problem, there is also an externality related to the good's production and/or consumption. Since the NGOs concern is the externality problem itself, it is natural that they advocate for stricter standards, compared to the social planner who wishes to maximize total welfare and sees the externality as just one component of this maximization problem. ${ }^{45}$ At the same time, governments possess coercive power that the NGOs usually lack. As a result, a government may impose mandatory standards, like MQS, while NGOs can confer labels only to those firms that voluntarily conform to their norms. The comparison between regulator-set MQS and voluntary labels set by an NGO, as well as issues concerning the coexistence and interaction of these instruments, form an important topic in the related literature. In order to delve a bit further into these issues, consider a good such that individual utility is positively affected not only by the quality level of the product consumed, but also by the average quality level $E$ of all product units in the market. Individual utility is described by the following variant of equation (1):

$$
U=\theta q-p+\gamma E
$$


The presence of $E$ constitutes an externality: with a large number of consumers, each individual consumer has only an infinitesimal impact on $E$ (assume it zero), while his utility depends strongly on quality choices made by the rest of the population. Two examples, both related to environmental externalities, typically motivate the use of the above utility function. First, the case of fresh produce available in both, organic and standard form. Because fertilizers are excluded from its production, organic produce provides health benefits, which translate into a higher value of $q$ relative to its standard counterpart. At the same time, the higher its market share, the lower the total use of fertilizers and the corresponding environmental harm, and therefore the higher the value of $E$ will be. The latter is an effect that is not taken into account by any single individual choosing the right type of produce in order to maximize their utility. The second example relates to the "warm glow" effect consumers may feel when making a "socially responsible" decision. Even if different types of a good provide exactly the same consumption benefits and no consumer can significantly affect $E$ through their product choice, more environment-friendly types of the good are characterized by a higher $q$ because of the satisfaction from "doing the right thing." 46

We first compare the impact of MQS to that of an NGO label in a competitive market, assuming initially that both are set at the same level, $\widetilde{q}$. Heyes and Maxwell (2004) consider a market served by a continuum of firms indexed by a parameter $\omega$, distributed on $[\underline{\omega}, \bar{\omega}]$, reflecting a firm's cost disadvantage in providing a given quality level. Each firm produces a single unit of some good which is sold to a particular consumer. Consumers are identical, purchase one unit, and their willingnessto-pay increases with quality: $p=p(q)$, with $p^{\prime}>0, p^{\prime \prime}<0$, and $p(\underline{q})>0 .{ }^{47}$ Without some form of third-party signaling, only the lowest quality level $\underline{q}$ is produced. While the non-coercive nature of the NGO label allows the basic quality to coexist alongside $\widetilde{q}$, the MQS imposes $\widetilde{q}$ as single quality in the market. The condition for a firm $i$ to adopt the label is $\omega_{i} \leq \omega^{N G O} \equiv(p(\widetilde{q})-p(\underline{q})) / \widetilde{q}$, while the condition for complying with the MQS-rather than exiting the market-is $\omega_{i} \leq \omega^{S} \equiv p(\widetilde{q}) / \widetilde{q}$. Obviously, $\omega^{S}>\omega^{N G O}$, implying that a larger number of firms decide to comply with an MQS 
rather than a label at the same level. This is intuitive since in case of non-compliance, the label offers firms a more attractive alternative than the one offered by MQS. Average quality in the market is obviously higher under the MQS, but the ranking of the two instruments with respect to consumption benefits is ambiguous, since it is unclear whether it is socially optimal to have all the producers with $\omega \in\left(\omega^{N G O}, \omega^{S}\right]$ producing $\widetilde{q}$ instead of $\underline{q}$.

If the comparison between a MQS and an NGO-set label yields an ambiguous ranking when performed at the same standard $(\widetilde{q})$, allowing each agency to set its preferred standard makes ranking impossible. Note, however, a small paradox: while the regulator is interested in total welfare and the NGO cares only about the average quality-level consumed per se, the regulator's instrument is more efficient in maintaining average quality, whereas the NGO's instrument may produce higher total welfare. This suggests that the two instruments better be used together. Heyes and Maxwell (2004) examines a sequential game where at the first stage the regulator chooses the level of MQS, at the second stage the NGO chooses the level of a voluntary label, and at the third stage firms decide their quality level. While the sign of the slope of the NGO's reaction function to MQS cannot be determined unambiguously, it turns out that a properly designed MQS performs better when coupled with an NGO-set label.

Considering that the continuum of consumers is served by a single firm, Bottega and De Freitas (2009) compares consumer welfare under the two regimes, noting that, while the MQS allows for only a single quality, the non-coercive nature of the label set by the NGO induces the monopolist to introduce two distinct qualities: the basic one, $\underline{q}$, and a certified high quality, $\widetilde{q}{ }^{48}$ Unless $\underline{q}$ and/or $\gamma$ are too high, a MQS increases consumer welfare and profits. ${ }^{49}$ With the NGO label consumers with "middle-high" willingness to pay are worse-off. This is due to the fact that the label may create excessive differentiation, leaving those consumers with the choice between a quality that is lower than what they could purchase under MQS, and one that is higher but too expensive.

As for the interaction between the NGO label and the MQS, in Bottega and De Freitas (2009) 
the two instruments are set simultaneously. The presence of the label reduces the role of the MQS to control for excessive differentiation, leaving the NGO to primarily deal with the environmental target. This implies that the presence of a label pushes the optimal level of MQS downwards, but rather surprisingly, the NGO would prefer the MQS to be even lower! This is so because the introduction of the MQS corresponds to a low quality improvement that induces some consumers, ceteris paribus, to switch from high to low quality. MQS exert therefore a double influence on average quality: on the one hand they improve it through the improvement of low quality, but on the other hand they reduce it through the increase of the low quality's market share. As $\gamma$ increases, the social planner's target comes closer to that of the NGO, and the MQS is set at lower levels.

\section{The political economy of labels}

As we have seen, $q_{F} \gtrless q_{W}<q_{N G O}$, i.e., the label's level that is optimal for the firm is less (or sometimes more) stringent than the social planner's optimal level which, in turn, is less stringent than the level most desired by the NGO. ${ }^{50}$ The existence of three potential standard setters with differing preferences as to the optimal level of the standard introduces the "political economy of the label setting", i.e., a positive approach trying to identify the standard that will most likely be observed. The introduction of a label or a modification of its standard creates gainers and losers, who stand on opposite sides with respect to the implementation of such regulatory intervention. For instance, some interest groups may resist the introduction of "GM-free" labels while other groups may wish to increase the purity requirement for a product to be labeled as GM-free (see Giannakas et al. 2011). The relative political power of such groups, as well as the benefits at stake, will most likely shape the type of regulation finally observed.

Assume that: a) a social planner sets an MQS and/or an NGO sets a label; b) the industry may resist the mandatory application of either if it reduces its profits; c) the intensity of the industry's resistance is directly related to the profit difference in the presence or absence of standard(s). Heyes 
and Maxwell (2004) shows that, first, "the threat of industry resistance leads the [government] to decrease [the MQS] so as to raise the likelihood of implementation. In doing so the level of expected social welfare falls from its no resistance level." 51 Second, the presence of an NGO-set label that a MQS proposes to replace increases industry resistance to the MQS, having no clear impact on welfare. Finally, when the NGO label already exists and is expected to be maintained after an eventual introduction of MQS, it reduces resistance to the MQS proposal, thus facilitating its introduction.

Studying the opposite situation in which the industry sets the standard and the NGO resists, trying to pull its level up, Baron (2011) models resistance explicitly. After observing the industryset standard, the NGO spends some campaign amount $a$ pressurizing the industry to increase the label's level above the profit-maximizing one, while the labeling organization of the industry decides whether to concede or to spend an amount $r$ in fighting the campaign. The campaign's probability of success is $\rho=\frac{\beta a}{\beta a+r}$, where $\beta$ measures the strength of the NGO compared to the firm: $\beta$ is high when the NGO is strong and credible, the cause appeals to consumers, and/or the firm is vulnerable. ${ }^{52}$ Firms and the NGO play simultaneously, deciding $r$ and $a$, respectively. Each side's reaction function is derived by maximizing its expected net benefit, which is

$$
\begin{aligned}
& \widehat{\pi}=(1-\rho) \pi\left(q_{F}\right)+\rho \pi\left(q_{N G O}\right)-r \\
& \widehat{V}=(1-\rho) V\left(q_{F}\right)+\rho V\left(q_{N G O}\right)-a
\end{aligned}
$$

for the firm and the NGO, respectively, with $\pi(),. V($.$) , representing industry profits and NGO,$ respectively, at any level of the standard. As it turns out, the equilibrium $\left(a^{*}, r^{*}\right) \in \mathbb{R}_{+}^{2}$, implying that it is optimal for the NGO to undertake some positive campaign and for the firm to spend some amount fighting it. Using $\left(a^{*}, r^{*}\right)$ and the definition of $\rho$, Baron (2011) shows that the equilibrium 
value $\rho^{*} \in(0,1)$, and is strictly decreasing in $q_{F}$, but also in $q_{N G O}$ : very ambitious campaigns thus have a small probability of success. By increasing the standard above $q_{F}$, the industry benefits from mitigating the risk of a successful campaign, at the cost of lowering its profits if the campaign fails. At the first stage of the game, the industry chooses the label's standard by maximizing (8) under the constraint that $\rho=\rho^{*}(q)$. Baron (2011) shows that i) the optimal level $\widetilde{q}$ is such that $\rho^{*}(\widetilde{q})=\frac{\widetilde{q}-q_{F}}{q_{N G O}-\widetilde{q}}$, and ii) $q_{F}<\widetilde{q}<\frac{1}{2}\left(q_{F}+q_{N G O}\right)$, i.e., the industry-set standard is higher than its level under no social pressure, but lower than the average between the industry's and the NGO's ideal level.

Various firms may have divergent preferences regarding the label's standard. Offering an NGO label alongside an industry-set one offers an additional option to low-cost (low $\omega$ ) firms. Hence, the introduction of an NGO label next to an existing industry-set one may not reduce total industry profits, and meets no resistance. Fischer and Lyon (2012) shows the reverse as not being true. The introduction of an industry-set label alongside an existing NGO label may make the NGO worse off since, along with firms that in its absence would go unlabeled, it also attracts firms that would otherwise opt for the NGO label. When the latter group's market share is larger than the former's, the NGO label loses adherents, thus having to lower its standard and accept a lower average quality. If on the other hand, the firms' distribution is skewed towards the low-cost end, the introduction of the industry-set label allows the NGO to propose a stricter label, thus "creaming" the low-cost firms while leaving those with a higher cost to comply with the industry label. The resulting pair of labels produces a higher quality improvement, and the industry-set label meets no opposition from the NGO.

Note that in all the literature reviewed in this section, the government (or "public regulator"), whether a single setter, a first mover, or a simple player among others in the standard-setting game, has been considered as a sole agent with a single objective: total-welfare maximization. While this assumption is helpful in establishing an ideal benchmark, it obscures the fact that, even within 
a single government, different agencies may have differing objectives, perhaps for being subject to different pressure groups. Thus, while the declared objective of any labeling policy is mainly to provide information to consumers, the way such policy is applied may be influenced by the specific agenda of the institution responsible for its implementation. Some institutions may adapt the labeling policies they are responsible for in order to promote market development, others may give their priority to protecting national producers, national consumers, etc.. As a result, government-set labeling standards may differ significantly according to the government body that sets them (e.g., the Ministry of Agriculture, of Health, or of Trade). This may in some cases explain differences in standards across countries.

The case of GMO provides a good example of a wide divergence of governmental bodies administering the related labeling policies: the Ministry of Agriculture in Argentina and Japan, of Foreign Affairs in South Korea, of Health in Canada, along with the Canadian Food Inspection Agency, the FDA in the US, and the Ministry of Environment in the UK (Phillips and McNeill 2000). Such heterogeneity in public certification bodies most likely affects the orientation of the labeling programs, in terms of both their standards and application rules, and should therefore be taken into account in future research on the political economy of labels. ${ }^{53}$

While political economy considerations have been used extensively to explain the level of the label's standard, little has been done towards a positive analysis of the choice between voluntary and mandatory labels. ${ }^{54}$ Studying the 2012 California vote on whether mandatory labeling of GM food should be introduced, Zilberman et al. (2014) argues that voluntary labeling is economically feasible, and that mandatory labeling is used in order to shift part of the labeling cost to the GMO producers, and ultimately to the GMO consumers. ${ }^{55}$ Setting a median voter model, that paper concludes that the main reason for consumers voting against mandatory labeling was "... the claim that implementation [of mandatory labeling] would raise food prices for Californians by 400/year per household..." ${ }^{\circ 6}$ While this work constitutes a promising first step on the political economy of 
mandatory labeling, a lot remains to be done in this respect.

\section{Conclusion and agenda for future research}

In this paper we have reviewed the theoretical literature on quality labels in an effort to bring together, contrast, and explain its most important results concerning the efficiency of labeling and its potential side-effects. Our analysis reveals that in order to implement a label, the regulator (public or private) must take into account how the label interacts with existing market distortions and new distortions the label may potentially introduce. The first point is a typical second-best type of conclusion where, in the presence of two distortions-concentrated market structure and asymmetric information-correcting only one may make things worse. The second point highlights distortions related to either i) the certification process, ii) the label's standard, or iii) lobbying activities in favor of, or opposed to the imposition of the label. By bringing together what economic theory has said about labeling so far, we hope that this work will assist researchers in further developing the theory, as well as public and/or private managers in implementing adequate policy.

Despite the enormous progress of the theory of labels during the past ten years, a host of commonly observed phenomena still lack adequate explanation. For instance, why in some cases does the label lead to substantial price premia, while in others the prices of the labeled and unlabeled products are almost equal? And when there are no price premia, why do some products still un-

dergo costly certification? Why in some cases are there so many closely related labels? We conclude this work with some thoughts on topics that require further investigation. We have identified at least two areas that need urgent theoretical support: the impact of labels on the vertical supply chain, and consumers' misperceptions of information on labels and/or the true nature of the product-attribute to which a label refers.

With respect to vertical relations, note that the discussion on the presence of labels in the supply chain has been limited to the impact of end-product labels on the price-quantity decisions of 
intermediate stages. The important role that labels may play in determining the very structure of the supply chain has been neglected. Can the introduction of a label affect the incentive for vertical integration, and is its impact (if any) on the supply chain of the labeled and low-quality product symmetric? Can the label affect the output and participation decisions of an integrated firm in the input market (input foreclosure)? These are just some of the important questions that await investigation.

Not only is the existing literature limited in scope, it is also almost exclusively based on market interface models. The available results concerning the role of labels in the supply chain are therefore a priori limited to cases where the input is sold at a single price in an "impersonal" market, in which purchasers have no power. However, in many sectors, as for instance the retail market, downstream firms do have power as input purchasers. As a result, input provision is obtained through individual contracts between an upstream supplier and a downstream firm. The impact of labels in shaping such contracts is an important issue that has not received adequate attention. Downstream firms possessing market power as input purchasers may put pressure on producers to adopt a label. For example, Ibanez and Laye (2005) states that $53 \%$ of certified firms in the French wood supply chain were urged to adopt eco-certification by the retail sector. In the same way, the recent strategy of some retailers, like the French supermarket chain Carrefour, to label their own products implies that their suppliers have the obligation to meet the label's standards. Due to certification requirements, producers must bear additional costs that are client-specific. Labeling may consequently accentuate the well-known hold-up problem in the producer-retailer relation (Goldberg 1976). Theoretical work is needed in order to determine how labeling affects the vertical structure of the supply chain through the hold-up problem, and what role the labeling of inputs can play instead of, or along with, the labeling of the final product.

Consumers' misperception of the label's information may have three sources: complexity of the message, large number of closely related labels, and potential misperceptions of the true risks/benefits related to the label-related product attribute. There is an emerging empirical literature showing nu- 
tritional labels to be a prime example of labels suffering from misperceptions due to the complexity of the information they provide. According to Kiesel, McCluskey and Villas-Boas (2011), reading a nutritional label needs a substantial amount of time; as a consequence, consumers are often unable either to evaluate the information provided by the label, or to relate it to their diet planning. Using laboratory experiments, Baixauli et al. (2008) finds that information about fiber content does not increase the consumers' acceptance of the healthier diet option, because consumers either do not understand the information, or associate it with negative food characteristics.

At a closer look, nutritional labels may be viewed as packages containing multiple labels, each of which carries information about a single product characteristic. Among these characteristics, some are of a "vertical" nature, i.e., ceteris paribus consumers unanimously rank products according to whether they contain more or less of these characteristics, while others are "horizontal", i.e., they are desirable for some consumers and undesirable for others. There is eventually a crowding of information on the package, so that the presence of each of these individual labels creates a negative externality to the others. Since consumer groups are not unanimous about the relative importance of each individual characteristic, the aforementioned externality turns out to be one among consumer groups: the presence of information concerning one may make information gathering more difficult for the other. A theory of optimal labeling content should take into account this externality, along with the size of each consumers group, and the relative importance each characteristic has for the concerned groups. While the impact of nutritional labels on market structure and welfare is an emerging topic in experimental literature (see e.g. Kiesel and Villas-Boas 2013, and Berning, Chouinard, and McCluskey 2011) ${ }^{57}$ there is almost no theoretical research addressing these topics.

Ecolabels are an instance where confusion is created by the presence of a large number of closely related labels (see Brécard 2013). Despite the serious threats that label proliferation poses to the informative role of labeling, it has hitherto received inadequate attention. ${ }^{58}$ Central to the label proliferation problem is the issue of competition between certifiers. While some very inter- 
esting literature has emerged on this topic, the issue of the optimal number of labels has not been investigated, especially in relation to the negative externality (confusion) they create for each other. Moreover, little has been said about competition among for-profit certifiers over the capturing of label-induced rents, and its impact on label proliferation. ${ }^{59}$

Finally, all the surveyed literature assumes asymmetric information, but focuses on cases where consumers really know what they want, their only problem being their inability to perceive how each available product corresponds to their wants. In many cases, however, besides their aforementioned inability to perceive how much of a desirable attribute each available product incorporates, consumers may also be confused about the desirability of the attribute itself. The analysis must therefore be extended in order to include consumers' misperceptions of their own needs. These misperceptions may take the form of an over- or under-estimation of risks or benefits related to some product attributes (see Marette and Roosen 2011).

Consider for instance the significant difference in the perception of risks and benefits related to the consumption of GM products between consumers on the two sides of the Atlantic. Such differences cannot be explained by differing scientific evidence (both areas share essentially the same scientific knowledge), and since GM and GMO-free products are similar, cannot either be attributed to "taste" differences, unless one is ready to assume important differences in health riskaversion or environmental sensitivity between Americans and Europeans. ${ }^{60}$

A potential explanation for such divergence in the perception of GMO health-related risks could be the regulation itself, which (whether by its presence or absence) may affect perceptions. Thus, while the literature has hitherto recognized perceptions as the basis for regulation, the causality may in some cases run the other way. The possibility of labels affecting perceptions, and thus creating (instead of simply helping to satisfy existing) demand for the certified attribute, has been recognized by many studies in the literature. ${ }^{61}$ Yet we have found no theoretical work on modeling consumers' misperceptions as determinants of the label's desirability and optimal standard, or analyzing the 
political economy of labels in the presence of such misperceptions.

While we believe the aforementioned, mostly theoretical, issues are important in order to deepen our understanding of the workings of labels, we close the research agenda with a call for some empirical research. By presenting the labels' side-effects in a systematic way this work aims to contribute not only to the advancement of theory, but also to actual and future public debates about labeling (e.g., labels related to GMO, animal cloning, global warming, etc.). This contribution will certainly be enhanced if the labels' side effects identified in this work can be empirically tested, and their impact measured. The use of experimental, econometric, and simulation tools may help to quantify the effects of labels on the different actors' surplus. While the recent works of Kiesel and Villas-Boas (2013), Bontemps, Bouamra-Mechemache and Simioni (2013), and Marette (2014) constitute a good start, more research is urgently needed in this direction. 
Figures

Figure 1. Spence (1975)'s demand effect

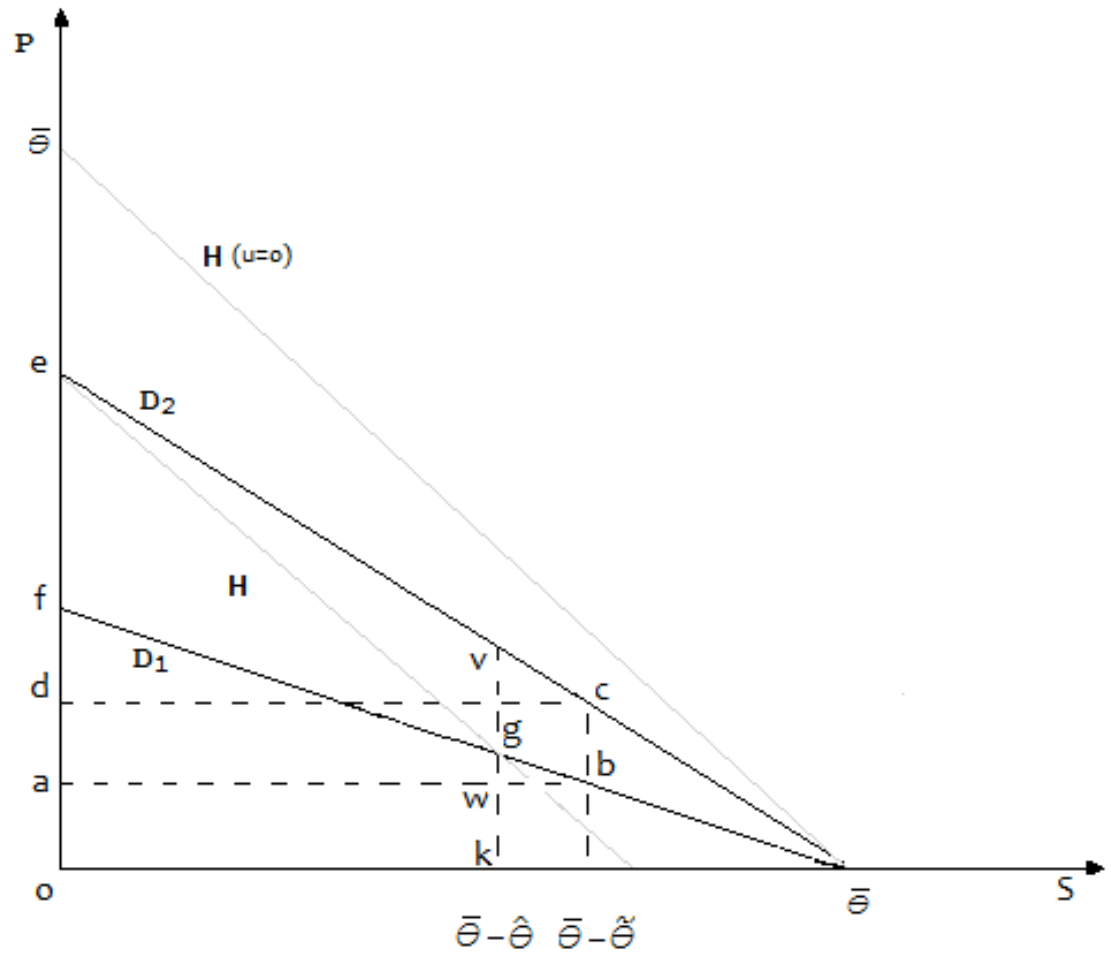


Figure 2. Merel and Sexton (2012)'s supply restriction effect

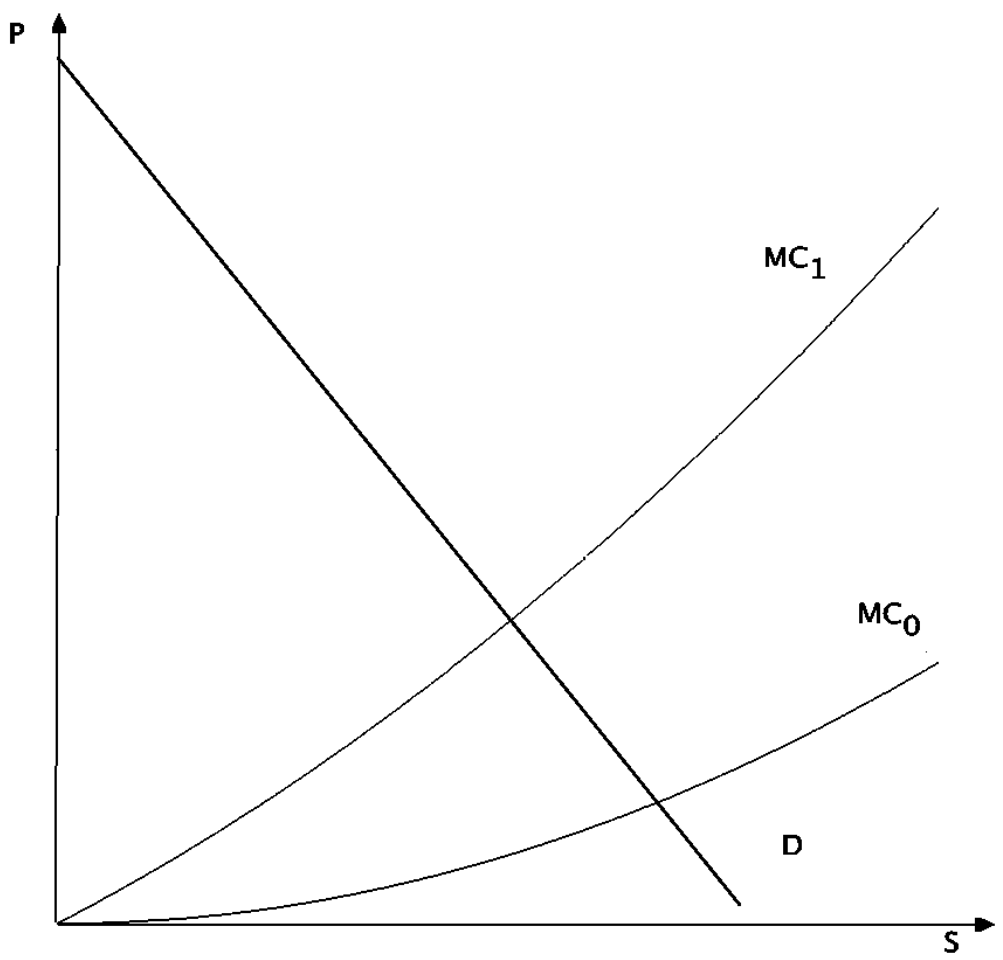




\section{Tables}

\section{Table 1. Examples of Different Categories of Labeling}

\begin{tabular}{llll} 
Reasons for labeling & Example of labeling & Origin & Owner of the label \\
\hline \hline Environmental protection & USDA Organic Certification & USA & Public \\
\hline Country of origin for fresh food & Country Of Origin Labeling & USA & Public \\
\hline Presence of GMO & Without Gene Technology Label & Germany & Public \\
\hline Solidarity trade & FAIRTRADE Certification Mark & Intl. & Not-for-profit organization \\
\hline Responsible management of the forests & FSC-Certification & Intl. & Not-for-profit organization \\
\hline Human health & OEKO-TEX Standards (textile) & EU & For-profit private certifier \\
\hline Names of quality agricultural products & Protected Designation of Origin & EU & Public \\
\hline
\end{tabular}


Table 2. The Effects of Costless Label on Market Equilibrium and the Actors' Payoffs

\begin{tabular}{cccccccccc} 
& $p_{2}$ & $p_{1}$ & $\pi_{2}$ & $\pi_{1}$ & $\Pi$ & $C S$ & $W$ \\
\hline \hline Market segmentation effect & + & - & + & - & + & + & + \\
\hline Differentiation effect & + & + & + & + & + & - & + \\
\hline Reverse differentiation effect & - & - & - & - & - & + & + \\
\hline Ranking effect & + & - & + & - & + & + & + \\
\hline
\end{tabular}


Table 3. The Impacts of Ranking Effect and Differentiation Effect on a Supply Chain

\begin{tabular}{|c|c|c|c|c|c|c|c|c|c|c|c|c|}
\hline & \multicolumn{2}{|c|}{$p_{2}$} & \multicolumn{2}{|c|}{$p_{1}$} & \multicolumn{2}{|c|}{$\pi_{2}$} & \multicolumn{2}{|c|}{$\pi_{1}$} & \multicolumn{2}{|c|}{$\Pi$} & \multirow[t]{2}{*}{$C S$} & \multirow[t]{2}{*}{$W$} \\
\hline & $U$ & $D$ & $U$ & $D$ & $U$ & $D$ & $U$ & $D$ & $U$ & $D$ & & \\
\hline Ranking effect & + & + & - & - & + & + & - & + & + & + & + & + \\
\hline Differentiation effect & + & + & + & + & + & + & $+/-$ & - & + & $+/-$ & $+/-$ & + \\
\hline
\end{tabular}


Table 4. Effects that Drive the Industry not to Set a Socially Optimal Label

\begin{tabular}{lc} 
& Label's level \\
\hline \hline Demand effect & Underprovision of quality \\
\hline Strategic effect & Overprovision of quality \\
\hline Profit margin effect & Overprovision or Underprovision of quality \\
\hline Supply restriction effect & Overprovision or Underprovision of quality \\
\hline Reservation-quality effect & Overprovision of quality \\
\hline
\end{tabular}




\section{References}

Akerlof, G. 1970. The market for "lemons": quality uncertainty and the market mechanism. Quarterly Journal of Economics 84(3):488-500.

Arnot, C., P. C. Boxall, and S. B. Cash. 2006. Do ethical consumers care about price? A revealed preference analysis of fair trade coffee purchases. Canadian Journal of Agricultural Economics 54:555-565.

Baixauli, R., A. Salvador, G. Hough, and S. M. Fiszman. 2008. How information about fibre (traditional and resistant starch) influences consumer acceptance of muffins. Food Quality and Preference 19:628-635.

Baltzer, K. 2011. Standards vs. labels with imperfect competition and asymmetric information. Economics Letters 114:61-63.

Barry, I., O. Bonroy, and P. G. Garella. 2014. Labeling by a Private Certifier and Public Regulation. Working paper n. 2014-07, Department of Economics, University of Milano.

Baron, D. P. 2011. Credence attributes, voluntary organizations, and social pressure. Journal of Public Economics 95:1331-1338.

Baksi, S., and P. Bose. 2007. Credence goods, efficient labelling policies and regulatory enforcement. Environmental and Resource Economics 37:411-430.

Beckmann, V., C. Soregaroli, and J. Wesseler. 2006. Coexistence Rules and Regulations in the European Union. American Journal of Agricultural Economics 88(5):1193-1199.

Berning, J., H. H. Chouinard, and J. J. McCluskey. 2011. Do positive nutrition shelf labels affect consumer behavior? Findings from a field experiment with scanner data. American Journal of Agricultural Economics 93:364-369.

Bonroy, O. 2009. On labels, competition and process attributes. Farm Policy Journal 6(4):4347.

Bonroy, O., and C. Constantatos. 2008. On the use of labels in credence goods markets. Journal 
of Regulatory Economics 33(3):237-252.

Bonroy, O., and S. Lemarié. 2012. Downstream labeling and upstream price competition. European Economic Review 56(3):447-360.

Bontemps, C., Z. Bouamra-Mechemache, and M. Simioni. 2013. Quality labels and firm survival: some first empirical evidence. European Review of Agricultural Economics 40(3):413-439.

Bottega, L., and J. De Freitas. 2009. Public, private and nonprofit regulation for environmental quality. Journal of Economics and Management Strategy 18(1):105-123.

Bouamra-Mechemache, Z., and J. Yu. 2012. Production Standard, Competition and Vertical Relationship. Mimeo.

Bowley, A. L. 1924. The Mathematical Groundwork of Economics. Oxford University Press, Oxford.

Brécard, D. 2013. Consumer Confusion over the Profusion of Eco-labels: Lessons from a Double Differentiation Model. Resource Energy Economics http://dx.doi.org/10.1016/j.reseneeco.2013.10.002

Bureau, J. C., E. Golzan, and S. Marette. 1999. Quality signaling and international trade in food products. European Review of Agricultural Economics 25: 437-462.

Cabral, L. M B. 2005. The economics of trust and reputation: a primer, Mimeo.

Carter, C. A., and G. P. Gruère. 2003. Mandatory Labeling of Genetically Modified Foods: Does it Really Provide Consumer Choice? AgBioForum 6(1\&2):68-70.

Caswell, J., and S. Anders. 2011. Private versus third party versus government labeling. In The Oxford Handbook of the Economics of Food Consumption and Policy, eds. J.L. Lusk, J. Roosen, and J.E. Shogren, 472-498. Oxford University Press.

Caswell, J., and M. Mojduszka. 1994. Using informational labeling to influence the market for quality in food products. American Journal of Agricultural Economics 78: 131-43.

Constantatos, C., and E. S. Sartzetakis. 1999. On commodity taxation in vertically differentiated markets. International Journal of Industrial Organization 17(8):1203-1217. 
Council of the European Union. 2006. Council Regulation (EC) No 510/2006 of 20 March 2006 on the protection of geographical indications and designations of origin for agricultural products and foodstuffs. Official Journal of the European Union L 93:12-25.

Crampes, C., and A. Hollander. 1995. Duopoly and Quality Standards. European Economic Review 39:71-82.

Cremer, H., and J-F. Thisse. 1999. On the taxation of polluting products in a differentiated industry. European Economic Review 43(3):575-594.

Crespi, J. M., and S. Marette. 2001. How Should Food Safety Certification Be Financed? American Journal of Agricultural Economics 83:852-861.

Crespi, J. M., and S. Marette. 2003. Some Economic Implications of Public Labeling. Journal of Food Distribution Research 34(3):83-94.

Crespi, J. M., and S. Marette. 2005. Eco-labelling Economics: Is Public Involvement Necessary? In Environment, Information and Consumer Behaviour, ed. S. Krarup, and C. S. Russell, 93-110. Cheltenham: Edward Elgar.

Darby, M., and E. Karni. 1973. Free competition and the optimal amount of fraud. Journal of Law and Economics 16(1):67-88.

Desquilbet, M., and D. S. Bullock. 2009. Who Pays the Costs of Non-GMO Segregation and Identity Preservation? American Journal of Agricultural Economics 91(3):656-672.

Disdier, A. C., and S. Marette. 2012. Taxes, minimum-quality standards and/or product labeling to improve environmental quality and welfare: Experiments can provide answers. Journal of Regulatory Economics 41(3):337-357.

Dixit, A. 1979. A model of duopoly suggesting a theory of entry barriers. Bell Journal of Economics 10(1):20-32.

Dranove, D., and G. Z. Jin. 2010. Quality disclosure and certification: theory and practice. Journal of Economic Literature 48:935-963. 
Drichoutis, A. C., Nayga R. M., and Lazaridis, P. 2011. Nutritional Labeling. In The Oxford Handbook of the Economics of Food Consumption and Policy, eds. J.L. Lusk, J. Roosen, and J. E. Shogren, 520-545. Oxford University Press.

Dulleck, U., and R. Kerschbamer. 2006. On doctors, mechanics, and computer specialists: The economics of credence goods. Journal of Economic Literature 44:5-42.

Fischer, C., and T. P. Lyon. 2012. Competing Environmental Labels. Mimeo, 40.

Fulton, M., and K. Giannakas. 2004. Inserting GM products into the food chain: The market and welfare effects of different labeling and regulatory regimes. American Journal of Agricultural Economics 86(1):42-60.

Gabszewicz, J., and I. Grilo. 1992. Price Competition when Consumers are Uncertain about which firm sells which quality. Journal of Economics and Management Strategy 1(4):629-649.

Gabszewicz, J. and J. Thisse. 1979. Price competition, quality and income disparities. Journal of Economics Theory 20:340-359.

Garella, P. G., and E. Petrakis. 2008. Minimum quality standards and consumers' information. Economic Theory 36(2):283-302.

Giannakas, K. 2002. Information Asymmetries and Consumption Decisions in Organic Food Product Markets. Canadian Journal of Agricultural Economics 50:35-50.

Giannakas, K., N. Kalaitzandonakes, A. Magnier and K. Mattas. 2011. Economic Effects of Purity Standards in Biotech Labeling Laws. Journal of Agricultural \& Food Industrial Organization $9(1): 1-45$.

Giannakas, K., and A. Yiannaka. 2008. Market and Welfare Effects of Second-Generation, Consumer-Oriented GM products. American Journal of Agricultural Economics 90(1):152-171.

Goldberg, V. P. 1976. Regulation and Administered Contracts. Bell Journal of Economics $7(2): 426-448$.

Golan, E., F. Kuchler, and L. Mitchell. 2001. Economics of Food Labeling. Journal of Con- 
sumer Policy 24:117-184.

Hamilton, S. F., and D. Zilberman. 2006. Green markets, eco-certification, and equilibrium fraud. Journal of Environmental Economics and Management 52:627-644.

Hainmueller, J., J. M. Hiscox, and S. Sequeira. 2011. Consumer Demand for the Fair Trade Label: Evidence from a Field Experiment. SSRN.

Harbaugh, R., J. W. Maxwell and B. Roussillon. 2011. Label Confusion: The Groucho Effect of Uncertain Standards. Management Science 57(9):1512-1527.

Heyes, A. G., and J. W. Maxwell. 2004. Private vs. public regulation: political economy of the international environment. Journal of Environmental Economics and Management 48:978-996.

Ibanez, L., and G. Grolleau. 2008. Can ecolabeling schemes preserve the environment? Environmental and Resource Economics 40:233-249.

Ibanez, L., and J. Laye. 2005. Stratégies d'Ecocertification: ou comment le rêve des uns peut faire le bonheur des autres. Cahier Scientifiques du Bois 3:325-332.

Krarup, S., and C. S. Russell. 2005. Environment, Information and Consumer Behaviour. Cheltenham: Edward Elgar.

Kiesel, K., J. J. McCluskey, and S. B. Villas-Boas. 2011. Nutritional labeling and consumer choices. Annual Review of Resource Economics 3:141-158.

Kiesel, K., and S. B. Villas-Boas. 2013. Can information costs confuse consumer choice? Nutritional labels in a supermarket experiment. International Journal of Industrial Organization 31:153-163.

Lapan, H., and G. Moschini. 2004. Innovation and Trade with Endogenous Market Failure: The Case of Genetically Modified Products. American Journal of Agricultural Economics 86(3):634648.

Lapan, H., and G. Moschini. 2007. Grading, minimum quality standards, and the labeling of genetically modified products. American Journal of Agricultural Economics 89(3):769-783. 
Lapan, H., and G. Moschini. 2009. Quality certification standards in competitive markets: When consumers and producers (dis)agree. Economics Letters 104(3):144-147.

Larue, B., S. Pouliot, and C. Constantatos. 2009. Exports to Smuggle and Smuggling Technologies. Review of International Economics 17:476-493.

Leland, H. 1979. Quacks, Lemons and Licensing: A Theory of Minimum Quality Standards. Journal of Political Economy 87:1328-1346.

Lence, S. H., S. Marette, D. J. Hayes and W. Foster. 2007. Collective Marketing Arrangements for Geographically Differentiated Agricultural Products: Welfare Impacts and Policy Implications. American Journal of Agricultural Economics 89(4):947-963.

Lusk, J. L., M. Jamal, L. Kurlander, M. Roucan, and L. Taulman. 2005. A meta-analysis of genetically modified food valuation studies. Journal of Agricultural and Resource Economics $30(1): 28-44$.

Lusk, J. L., and S. Marette. 2012. Can labeling and information policies harm consumers? Journal of Agricultural and Food Industrial Organization 10(1):1-7.

Mahenc, P. 2009. Wasteful labeling. Journal of Agricultural and Food Industrial Organization $7: 1-17$.

Manasakis, C., E. Mitrokostas, and E. Petrakis. 2013. Certification of Corporate Social Responsibility Activities in Oligopolistic Markets. Canadian Journal of Economics 46(1):282-309.

Marette, S. 2007. Minimum safety standard, consumers' information and competition. Journal of Regulatory Economics 32(3):259-285.

Marette, S. 2014. Economic Benefits Coming from the Absence of Labels Proliferation. Journal of Agricultural and Food Industrial Organization 0(0):1-9.

Marette, S., and J. Roosen. 2011. Bans and Labels with Controversial Food Technologies. In The Oxford Handbook of the Economics of Food Consumption and Policy, eds. J. L. Lusk, J. Roosen, and J. E. Shogren, 499-519. Oxford University Press. 
Mason, C. F. 2011. Eco-labeling and market equilibria with noisy certification tests. Environmental and Resource Economics 48:537-560.

Mattoo, A., and A. Singh. 1994. Eco-labelling: Policy considerations. Kyklos 47:53-65.

McCluskey, J. 2000. A Game Theoretic Approach to Organic Foods: An Analysis of Asymmetric Information and Policy. Agricultural and Resource Economics Review 29(1):1-9.

Mérel, P., and R. J. Sexton. 2012. Will geographical indications supply excessive quality? European Review of Agricultural Economics 39(4):567-587.

Moschini, G., L. Menapace and D. Pick. 2008. Geographical Indications and the Provision of Quality. American Journal of Agricultural Economics 90:794-812.

Motta, M. 1993. Endogenous Quality Choice: Price vs. Quantity Competition. Journal of Industrial Economics 47:113-131.

Mussa, M., and S. Rosen. 1978. Monopoly and product quality. Journal of Economic Theory 18:301-317.

National Research Council. 2010. Impact of Genetically Engineered Crops on Farm Sustainability in the United States . Washington, DC: The National Academies Press.

Noussair, C., S. Robin, and B. Ruffieux. 2004. Do consumers really refuse to buy genetically modified food? The Economic Journal 114(492):102-120.

Phillips, P. W. B., and H. McNeil. 2000. A Survey of National Labeling Policies for GM Foods. AgBioforum 3(4):219-224.

Roe, B. E., and I. Sheldon. 2007. Credence good labeling: The efficiency and distributional implications of several policy approaches. American Journal of Agricultural Economics 89(4):10201033.

Roe, B. E., M. F. Teisl, and C. R. Deans. 2014. The Economics of Voluntary Versus Mandatory Labels. Annual Review of Resource Economics 6.

Ronnen, U. 1991. Minimum quality standard, fixed costs, and competition, Rand Journal of 
Economics 22:490-504.

Shaked, A., and J. Sutton. 1982. Relaxing price competition through product differentiation. Review of Economic Studies 49(1):3-13.

Spence, A. M. 1975. Monopoly, quality, and regulation. Bell Journal of Economics 6:417-429.

Spence, A. M. 1976. Product differentiation welfare. American Economic Review 66(2):407414.

Teisl, M. F., and B. E. Roe. 1998. The Economics of Labeling: An Overview of Issues for Health and Environmental Disclosure. Agricultural and Resource Economics Review 28(2):140150.

Teisl, M. F., and B. E. Roe. 2005. Evaluating the Factors that Impact the Effectiveness of Ecolabelling Programs. In Environment, Information and Consumer Behaviour, ed. S. Krarup, and C. S. Russell, 65-90. Cheltenham: Edward Elgar.

Teisl, M. F., B. E. Roe, and R. L. Hicks. 2002. Can eco-labels tune a market? Evidence from dolphin-safe labeling. Journal of Environmental Economics and Management 43:339-359.

Tirole, J. 1988. The Theory of Incentives in Procurement and Regulation. Cambridge: MIT Press.

Yale Program on Forest Policy and Governance. 2008. Assessing USGBC's policy options for forest certification \& the use of wood and other bio-based materials. Report, 39 .

Zago, A. M., and D. Pick. 2004. Labeling policies in food markets: Private incentives, public intervention, and welfare effects. Journal of Agricultural and Resource Economics 29:150-165.

Zilberman, D., S. Kaplan, E. Kim, and G. Waterfield. 2014. Lessons from the California GM Labeling Proposition on the State of Crop Biotechnology. In Handbook on Agriculture, Biotechnology, and Development, ed. S. Smyth, D. Phillips, and P. Castle, Chapter 34. Cheltenham: Edward Elgar. 


\section{Notes}

${ }^{1}$ See Dranove and Jin (2011) for a theoretical and empirical survey of quality disclosure and certification.

${ }^{2}$ In many places in the literature the informational categorization applies to goods rather than attributes. Since few goods are purchased for only a single attribute, and a good may therefore fall into more than one category, categorization according to attributes is more rigorous. However, at some places we follow the literature and refer to search, experience, or credence goods (instead of attributes), meaning goods purchased mainly for an attribute falling in one of these categories.

${ }^{3}$ A typical example of a credence good is a repair service. Only the seller (the expert) knows the appropriate type of repair and the amount of service provided. The consumer is potentially confronted with two forms of information asymmetry. First he does not know the type of reparation needed, and second, may not be able to observe whether the suggested treatment was provided or not (Darby and Karni 1974, and Dulleck and Kerschbamer 2006). For some credence goods, such as the ones related to "process attributes", only the second form of information asymmetry applies.

${ }^{4}$ Labeling may provide information for both search and experience attributes, but its importance as an information provider is generally very low. For instance, a vegetable's freshness (a search attribute) can often be ascertained by just looking at it, thus leaving little opportunity for producers to deceive consumers about the quality of the product they sell. In the same way, when the information can be acquired after consuming the good there exist market mechanisms (founded on "trust" and "reputation") that deal satisfactorily with the asymmetric information problem (see e.g. Cabral 2005).

${ }^{5}$ Strictly speaking, the "reputation" mechanism may in some cases work in credence-goods markets, such as the one for repair services (see Dulleck and Kerschbamer 2006). For the special case of process attributes, building a "reputation" mechanism cannot be excluded either, yet is contingent on very restrictive assumptions (see Marette 2007, Bonroy and Constantatos 2008, and Garella and 
Petrakis 2008).

${ }^{6}$ Teisl and Roe (1998) considers Type III labels to be more objective, while Type I labels more normative.

${ }^{7}$ More precisely, $p^{U}=\frac{b_{2}\left(b_{2} q_{1}+q_{2}\right)}{\left(1+b_{2}\right)\left(b_{2}+b_{2} q_{1}+q_{2}\right)}, p_{1}^{L}=\frac{b_{2} q_{1}}{b_{2}+b_{2} q_{1}-q_{1}^{2}+q_{2}+q_{1} q_{2}}$, and $p_{2}^{L}=\frac{b_{2}\left(q_{2}-q_{1}^{2}+q_{1} q_{2}\right)}{b_{2}+b_{2} q_{1}-q_{1}^{2}+q_{2}+q_{1} q_{2}}$.

${ }^{8}$ See Bureau, Golzan and Marette (1999) for such an analysis in an international trade context.

${ }^{9}$ Table 2 summarizes the effects of labeling ("+" for an increase and "-" for a reduction) on prices $p_{i}$, producers' profit $\pi_{i}$, industry's profit $\Pi$, consumers surplus $S C$ and total welfare $W$, with $i=1,2$. For instance, the market segmentation effect increases the price of the high-quality product $\left(p_{2}\right)$, and decreases that of the low-quality one $\left(p_{1}\right)$.

${ }^{10}$ The novelty in Matoo and Singh (1994) is that the segment of quality-indifferent consumers is no longer represented by a single consumer with inelastic demand, but by a more conventional demand function, smoothly decreasing in price. A similar situation arises in the wine market where one group of consumers is willing to pay more for controlled origin wines, while another purchases according to price.

${ }^{11}$ Unless the consumers' distribution is sufficiently skewed towards the high end for the gainers to account for a substantial part of the consumer population. With a uniform distribution, the total consumers' surplus reduction is guaranteed.

${ }^{12}$ This rules out any sort of price signaling.

${ }^{13}$ This analysis is based on Bonroy and Constantatos (2008). In Gabszewicz and Grilo (1992), both qualities are produced at equal cost.

${ }^{14}$ The few exceptions are found in the literature on GMO. Fulton and Giannakas (2004) considers a monopolist supplier of GM seed (the life-science company) selling to competitive farmers and facing competition by a perfectly competitive traditional-seed sector. It shows that concerning the label's introduction, the interest of consumers, producers and the GM-seed supplier are rarely aligned. Lapan and Moschini (2007), focusing on the relation between the label's optimal standard 
and the welfare of each part of the supply chain, will be examined in the subsection Private vs. public labels.

${ }^{15}$ Note that the second generation of GMO-containing final products (GM products) has attributes that increase the attractiveness of GMO in the eyes of consumers. Giannakas and Yiannaka (2008) shows that the introduction of such GM products can change the relationship between GM, and conventional and organic products from vertical to horizontal product differentiation, thus improving the market acceptance of agricultural biotechnology.

${ }^{16}$ Table 3 presents the impact of the ranking and differentiation effects on each supply chain. Subscripts 2 and 1 refer to the high- and low-quality supply chain, respectively, while " $U$ " and " $D$ ", show the position in the supply chain (upstream, or downstream) to which the impact refers. For instance, the impact of the ranking effect on both, the input price $\left(p_{2}, U\right)$ and the final-good price $\left(p_{2}, D\right)$ of the high-quality supply chain is positive. The table contains three parts: the first shows impact on prices (columns $p_{2}, p_{1}$ ), the second on profits (columns $\pi_{2}, \pi_{1}$, and $\Pi$ ), and the third on consumer surplus (column $C S$ ), and total welfare (column $W$ ).

${ }^{17}$ This effect is extreme when the Bertrand Paradox holds (see e.g. Crespi and Marette 2001).

${ }^{18}$ Based on a database on French dairy firms, Bontemps, Bouamra-Mechemache and Simioni (2013) shows that engaging in a producers' association in order to share the labeling cost is particularly advantageous for small firms.

${ }^{19}$ Crespi and Marette (2001) conditions this conclusion holds on the opportunity cost of public funds being sufficiently low.

${ }^{20}$ In analyzing agricultural markets, Lapan and Moschini (2004) considers the low quality (GM product) as being the new product. While this history-based approach is suitable for comparing the market outcome before and after the introduction of the GM product, for our purposes it is as if in the absence of labeling the high quality were non-existent. Until the certification cost is paid, its presence is eclipsed by that of the low quality. 
If under asymmetric information consumers expect some average (instead of just the low) quality, as in Zago ad Pick (2004), labeling corresponds to the introduction of two new qualities (high and low) instead of one, along with the simultaneous withdrawal of the expected-quality "product" that consumers perceived under asymmetric information.

${ }^{21}$ Roe, Teisl and Deans (2014) offers an excellent analysis of the factors affecting $\Delta \pi, \Delta \Pi$, and $\triangle C S$.

${ }^{22}$ It is, of course, impossible to force the high quality firm alone to label its product, for it always has the option to forego the payment of $F$, and sell its product as low quality. In Desquilbet and Bullock (2009), the group of non-IP grains is composed of GM grain and grain that "sprouts from non-GM seed, but producers take no steps to prevent its possible commingling with GM grain."

${ }^{23}$ As tax-\&-subsidy schemes necessarily involve redistribution, it is hard to disentangle their claims to efficiency from any redistribution-related motivations there may be.

${ }^{24}$ Note that $\underline{t}<\bar{t}$ implies $F \leq \pi_{2}+\pi_{1}:$ a necessary condition for having the two qualities present under full information is that the certification cost does not exceed the sum of their profits.

${ }^{25}$ The European regulator is not interested in subsidizing the imported GM-free product through redistribution of the IP cost. Instead, GM-free imports are encouraged by imposing additional and potentially artificial costs on the GM product (traceability costs).

${ }^{26}$ Third-party labeling of low- instead of high-quality firms is always costlier than self-labeling: by increasing the cost of low quality, third-party labeling increases the high-quality's market share, along with the number of firms that must be inspected (see Baski and Bose 2007).

${ }^{27}$ Consider, for example, the case of the French label "Label Rouge", requiring French farmers to use $70 \%$ to $80 \%$ of cereals in their animal feed. The entire production of a labeled farmer is certified, although only a part of it has been inspected.

${ }^{28}$ Hargaugh et al. (2011) shows that when a questionable producer joins a group of certified firms, the reputation of a collective label may also be damaged. Such an effect reduces, in turn, the 
benefit that the questionable producer may derive from adopting the label.

${ }^{29}$ The analysis draws on Hamilton and Zilberman (2006). Mason (2011) shows that fraud may also exist in environments where the certification test is noisy, with high quality-firms more likely to pass than low quality-firms.

${ }^{30}$ Ibanez and Grolleau (2008) finds a similar result when the certification cost is a sunk cost. The authors assume that a high-quality firm does not bear the same sunk cost as a low-quality firm, $F_{2} \neq F_{1}$. In such an environment, positive certification costs increase the level of purity in the market only when $F_{2}$ is sufficiently low and $F_{1}$ sufficiently high. If these conditions are not respected none of the firms produce the high-quality product, and the label is never acquired.

${ }^{31}$ The latter effect does not work when the detection frequency of a firm is not endogenous, see Hamilton and Zilberman (2006).

${ }^{32}$ See Caswell and Anders (2011) for a categorization of labels according to their owners.

${ }^{33}$ The term "industry" is not so clear when the industry is composed of a number of heterogeneous firms. In that case the identification of the decision maker is problematic: is it the biggest firm, the median size one, the one producing the top quality, or other? This standard problem in the collective choice literature is usually sidestepped by assuming the industry is composed of similar firms. While this assumption is rooted in the need to simplify the analysis, it cannot be considered as unreasonable, since trade unions are usually formed of firms with similar interests with regard to certain issues.

One should not confuse the case where a firm (or group of firms) chooses the label's standard with self-labeling, where, obviously, issues of credibility, cheating and monitoring arise. Here, we assume the existence of private parties certifying the level proposed by the "industry", or simply, the high-quality firm. Thus, the standard is set at the profit maximizing level and the agency simply certifies whether a given firm's product is indeed of the claimed quality level.

${ }^{34}$ Equivalently, one may examine the nature of the upward shift that a quality increment produces 
on the demand curve. If the willingness-to-pay for units close to the origin increases more (less) than it does for subsequent units, the monopolist undersupplies (oversupplies) quality. Compared to a parallel shift in demand-where the monopolist and the social planner offer the same quality-this implies a more pronounced shift close to (away from) the origin.

${ }^{35}$ Lapan and Moschini (2009) shows that the equivalent of the demand effect in competitive markets leads to a higher (lower) industry-set standard, compared to the social planner's optimum, if the demand function is log-convex (log-concave).

${ }^{36}$ This incentive disappears if the market is covered in the duopoly equilibrium, as, for instance, in Roe and Sheldon (2007), unless the social planner attaches more weight to consumer surplus than to profits. Note also that no matter whether they increase or reduce total consumer surplus, changes in product differentiation are never Pareto improvements since they have opposite welfare effects on consumers at the high or the low end of the distribution.

${ }^{37}$ If we adopt a more general cost function of the type $F(q)=k q^{\alpha}, \forall \alpha>2$, firm 2 wishes less differentiation than in the $\alpha=2$ case, and private labels will set lower standards than public ones. This result may eventually be reversed if the cost-of-quality function is very flat, i.e., for $\alpha<\widetilde{\alpha} \in(1,2)$. We have not verified the existence of $\widetilde{\alpha}$.

${ }^{38}$ E.g., Council of the European Union (2006), Article 5. We are referring to European type GIs that not only refer to origin, but also guarantee that the production process complies with certain norms. In this respect, GIs become quality standards that even some producers within the designated area may fail to meet. For such GI labels, origin is a necessary but not sufficient condition.

${ }^{39}$ Most organizations responsible for labeling cheese, wine and other agricultural products according to GIs do not (or are not allowed to) directly control total quantity.

${ }^{40}$ In Mérel and Sexton (2012) it is called "demand effect".

${ }^{41}$ Actually, Spence (1975) presents the case where, contrary to the case in Mérel and Sexton (2012), "average costs go up faster than marginal costs as quality is increased" (see Spence 1975, 
Footnote 4). As a result, Spence's work predicts quality underprovision by the constrained monopolist, while in Mérel and Sexton (2012) a monopolist constrained to price at marginal cost will overprovide quality.

${ }^{42}$ This is, for instance the rationale behind export taxes.

${ }^{43}$ Average costs, whether in quality or in quantity, are increasing only if the corresponding marginal cost is increasing. Obviously, if the marginal cost is flat in quality, the organization has no means to increase it, while if it is flat in quantity producer surplus is always zero.

${ }^{44}$ The slope of line $H$ is equal to 1 ; for $u=0$ the line intersects the axes at points $(0, \bar{\theta})$ and $(\bar{\theta}, 0)$; increases in $u$ shift $H$ parallel-downwards. For simplicity, quality $q_{2}$ on the diagram has been chosen in such a way that, at price equal to zero the $\bar{\theta}$ consumer is just indifferent to either buying the product of quality $q_{2}$ or refraining from making a purchase.

${ }^{45}$ See proposition 2 in Bottega and Freitas (2009). In this section we assume that the government acts as social planner.

${ }^{46}$ See Cremer and Thisse (1999), and Constantatos and Sartzetakis (1999) where consumers are distributed according to their environmental sensitivity, with $\theta=0$ representing the consumer who likes better environment but leaves it to others to take care of it.

${ }^{47}$ Since each firm sells in a segregated market with perfectly inelastic demand, each price is equal to the consumers' willingness to pay for the corresponding quality.

${ }^{48}$ The label allows for the introduction of a second quality, but whether this is profitable should be endogenous in the model. While in many instances the monopolist would indeed take advantage of this possibility, with preferences described by (1) (a variant of which is also used in Bottega and De Freitas 2009), she does not wish to introduce the lower-quality product (see Larue, Pouliot and Constantatos 2009).

${ }^{49}$ If $\underline{q}$ is higher than the individual consumer's optimal level (given the monopoly pricing), the MQS forces the consumption of a low quality that is too high. High values of $\gamma$, on the other hand, 
call for high MQS, and again may force consumers to consume a low quality that is still too high.

${ }^{50}$ Recall that when the demand effect prevails $q_{F}<q_{W}<q_{N G O}$. Bottega and De Freitas (2009) obtains this ranking in a monopoly market, and Manasakis, Mitrokostas and Petrakis (2013) in an oligopoly market with a Dixit-Spence-Bowley type of demand (Dixit 1979, Spence 1976, Bowley 1924).

${ }^{51}$ Proposition 2 in Heyes and Maxwell (2004).

${ }^{52}$ Important brand-name firms may have difficulty resisting the campaign, especially when resistance involves law suits.

${ }^{53}$ In the same spirit, in Beckmann, Soregaroli and Wesseler (2006) it is argued that the European Union decision to leave the scope of the coexistence between conventional, organic, and GMOusing agriculture to the discretion the Member States has led to a diversity of measures within the EU. It is shown that countries like Austria, Hungary, Luxembourg, Poland and The Slovak Republic that wish to ban GM crops have kept on with banning by introducing prohibitively restrictive regulations. Other countries, like the Czech Republic, Denmark, Germany, The Netherlands, Spain and Germany, have opted for less restrictive regulations, but combined them with liability rules enabling the compensation of non-GM farmers for damages due to the use of GM crops.

${ }^{54}$ See Roe, Teisl and Deans (2014) for a review of the available work.

${ }^{55}$ In terms of our mandatory labeling analysis, this corresponds to $t<1 \leq \bar{t}$.

${ }^{56}$ The vote took place on November 6th, 2012. Proposition 37, requiring "mandatory labeling of food sold to consumers made from plants or animals with genetic material changed in specified ways ... failed to pass with $51.5 \%$ of California voters opposing it..." (see Zilberman et al. 2014). Subsequently, however, "... Connecticut and Maine [became] the first and second states to approve a GM labeling law (see Roe, Teisl and Deans 2014)

${ }^{57}$ Kiesel and Villas-Boas (2013) and Berning, Chouinard, and McCluskey (2011) use field experiment to study the effect of grocery store nutritional labels on the sales of microwave popcorn. 
${ }^{58}$ Exceptions are Harbaugh, Maxwell and Roussillon (2011), Lusk and Marette (2012), and Brécard (2013).

${ }^{59}$ Barry, Bonroy and Garella (2014) is the first to formalize competition among private for-profit certifiers.

${ }^{60}$ A recent study (National Research Council 2010) highlights some positive externalities of the introduction of GM crops on soil and water quality.

${ }^{61}$ See for instance Caswell and Mojduszka (1996), and Carter and Gruère (2003). 